\title{
RESEARCH
}

Open Access

\section{Trends in prevalence, mortality, and morbidity associated with high systolic blood pressure in Brazil from 1990 to 2017: estimates from the "Global Burden of Disease 2017" (GBD 2017) study}

Bruno Ramos Nascimento ${ }^{1,2^{*}}$ (1), Luísa Campos Caldeira Brant ${ }^{1,2}$, Simon Yadgir ${ }^{3}$, Gláucia Maria Moraes Oliveira 4 , Gregory Roth ${ }^{3}$, Scott Devon Glenn ${ }^{3}$, Meghan Mooney ${ }^{3}$, Mohsen Naghavi ${ }^{3}$, Valéria Maria Azeredo Passos ${ }^{5}$, Bruce Bartholow Duncan ${ }^{6}$, Diego Augusto Santos Silva ${ }^{7}$, Deborah Carvalho Malta ${ }^{8,9}$ and Antonio Luiz Pinho Ribeiro

\begin{abstract}
Background: Hypertension remains the leading risk factor for cardiovascular disease (CVD) worldwide, and its impact in Brazil should be assessed in order to better address the issue. We aimed to describe trends in prevalence and burden of disease attributable to high systolic blood pressure (HSBP) among Brazilians $\geq 25$ years old according to sex and federal units (FU) using the Global Burden of Disease (GBD) 2017 estimates.
\end{abstract}

Methods: We used the comparative risk assessment developed for the GBD study to estimate trends in attributable deaths and disability-adjusted life-years (DALY), by sex, and FU for HSBP from 1990 to 2017. This study included 14 HSBP-outcome pairs. HSBP was defined as $\geq 140 \mathrm{mmHg}$ for prevalence estimates, and a theoretical minimum risk exposure level (TMREL) of 110-115 mmHg was considered for disease burden. We estimated the portion of deaths and DALYs attributed to HSBP. We also explored the drivers of trends in HSBP burden, as well as the correlation between disease burden and sociodemographic development index (SDI).

Results: In Brazil, the prevalence of HSBP is 18.9\% (95\% uncertainty intervals [UI] 18.5-19.3\%), with an annual 0.4\% increase rate, while age-standardized death rates attributable to HSBP decreased from 189.2 (95\%UI 168.5-209.2) deaths to 104.8 (95\%UI 94.9-114.4) deaths per 100,000 from 1990 to 2017. In spite of that, the total number of deaths attributable to HSBP increased $53.4 \%$ and HSBP raised from 3rd to 1st position, as the leading risk factor for deaths during the period. Regarding total DALYS, HSBP raised from 4th in 1990 to 2nd cause in 2017. The main driver of change of HSBP burden is population aging. Across FUs, the reduction in the age-standardized death rates attributable to HSBP correlated with higher SDI.

(Continued on next page)

\footnotetext{
* Correspondence: ramosnas@gmail.com

${ }^{1}$ Faculdade de Medicina, Universidade Federal de Minas Gerais, Belo Horizonte, MG, Brazil

${ }^{2}$ Hospital das Clínicas, Universidade Federal de Minas Gerais, Avenida Professor Alfredo Balena, 110, Belo Horizonte, MG, Brazil

Full list of author information is available at the end of the article
}

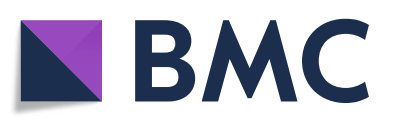

(0) The Author(s). 2020 Open Access This article is licensed under a Creative Commons Attribution 4.0 International License, which permits use, sharing, adaptation, distribution and reproduction in any medium or format, as long as you give appropriate credit to the original author(s) and the source, provide a link to the Creative Commons licence, and indicate if changes were made. The images or other third party material in this article are included in the article's Creative Commons licence, unless indicated otherwise in a credit line to the material. If material is not included in the article's Creative Commons licence and your intended use is not permitted by statutory regulation or exceeds the permitted use, you will need to obtain permission directly from the copyright holder. To view a copy of this licence, visit http://creativecommons.org/licenses/by/4.0/ The Creative Commons Public Domain Dedication waiver (http://creativecommons.org/publicdomain/zero/1.0/) applies to the data made available in this article, unless otherwise stated in a credit line to the data. 


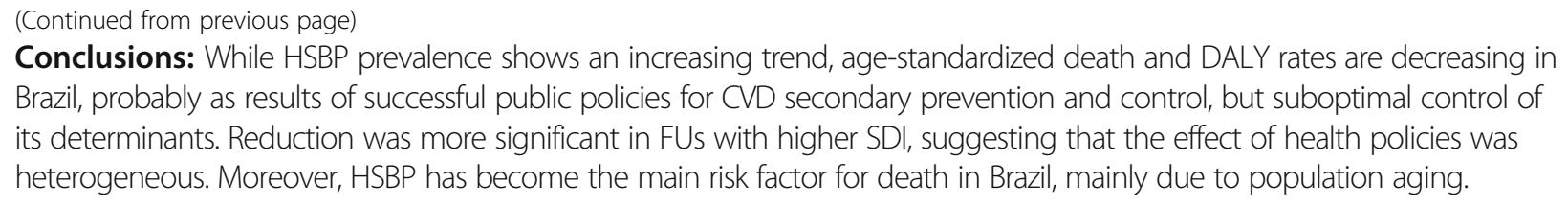

Keywords: Global burden of disease, Hypertension, Morbidity, Mortality, Epidemiology

\section{Background}

Cardiovascular disease (CVD) is the major cause of morbidity and mortality in developed countries, and the same trend has been observed in Brazil since the epidemiological transition, in the 1960s [1]. Besides being the leading cause of death and hospitalizations in the country, CVD also poses a significant economic burden [1]. Hypertension (HTN) is the most prevalent risk factor for CVD, affecting 32.3\% of Brazilian adults [2, 3].

HTN is associated with ischemic heart disease and stroke, the main causes of death in the country, and is also a risk factor for heart failure, chronic kidney disease, cognitive decline, and other diseases [4]. Thus, there is a recognized strong association of HTN with many diseases and early preventive and therapeutic interventions are available. However, the asymptomatic nature of the disease in most of its clinical course and the lack of awareness about the condition are contributing factors for its underdiagnosis, especially in early stages [1]. Published estimates suggest that among hypertensive young adults in the USA, less than $75 \%$ are aware of the diagnosis, only about $60 \%$ are adequately treated, and around $40 \%$ have adequate control [5]. Macinko et al. using data from Brazil National Health Survey conducted in 2013 found that $89 \%$ of hypertensive patients had contact with the health system in the past 2 years, but only $65 \%$ were aware of their condition, and 33\% had their BP under control [6]. In a cohort of Brazilian civil servants, results are similarly suboptimal, with $80.2 \%$ awareness among hypertensives and 53\% with adequate control [7].

Most of the basic pharmacological arsenal for HTN is freely available in the Brazilian Public Health System (Sistema Único de Saúde (SUS)), and national programs, especially in primary care, have been implemented to improve population awareness, early diagnosis, and adherence to HTN treatment [8]. However, the scope of these initiatives is still heterogeneous, and their practical results have not yet been adequately measured. Consistent epidemiological data are needed for the development of health policies in order to reduce the impact of HTN in Brazil.

The primary objective of the present study is to analyze the prevalence of and the burden of diseases attributable to high systolic blood pressure (HSBP) among Brazilians according to sex and federal units (FU) between 1990 and 2017, based on the estimates of the Global Burden of Disease 2017 study (GBD 2017). Additionally, we aimed to assess the correlation between HSBP burden and socioeconomic development.

\section{Methods \\ The Global Burden of Disease study}

The GBD study is a multinational research collaboration with the objective to produce consistent estimates of health problems related to more than 328 diseases and injuries in 195 countries and territories. A wide range of data sources (national surveillance-such as the National Health Survey, which measured blood pressure measurements in the Brazilian adult population in 2013 [3]vital records and verbal autopsy, published and unpublished disease registries, and published scientific literature) and methods were employed to produce specific results by age and sex for the years 1990-2017, updated annually for the entire time series. Estimation techniques imply that Brazilian data, when available, is weighted much more heavily than data from other geographies and primarily drives the estimates. Methods from the GBD 2017 study have been described in detail [9-11]. Methodological specificities of the GBD estimates in Brazil have been previously reported, for the GBD 2015 study [12]. Methods specific to the GBD estimation of HSBP and its burden have been reported for the GBD 2015 study as well [13].

\section{Methodology for the evaluation of risk factors in the GBD study}

GBD's Comparative Risk Analysis (CRA) is a comprehensive and comparable approach to individual quantification of risk factors, a tool for synthesizing risk evidence and risk-outcome associations. The conceptual CRA framework establishes a causal network of hierarchically organized (5 hierarchical levels) risks or causes that contribute to health outcomes, as well as the attributable burden by age, gender, cause, and location, allowing the quantification of risks or causes at any level of the structure. The relationship between risk exposures and socio-demographic development, as measured by the Sociodemographic Index (SDI), provides additional data on the magnitude of this social interaction [9]. 
The GBD CRA structure is based on the premise that the risk caused by a given exposure starts at a certain level and then increases as the exposure rises above that level. Four components feed into the calculations to estimate the burden attributable to a given risk-outcome pair: (1) the estimate of the measured burden metric for a cause (i.e., number of deaths, years of life lost (YLLs), years lived with disability (YLDs), or disability-adjusted life-years (DALYs) [10, 11, 14]), (2) the exposure levels for the risk factor, (3) the counterfactual level of risk factor exposure or theoretical minimum risk exposure level (TMREL), and (4) the relative risk of the outcome, related to the TMREL. For a given risk-outcome pair, the attributable DALYs as the total DALYs for outcome multiplied by the Population-Attributable Fraction (PAF) at the risk-outcome pair for a given age, sex, location, and year was estimated. The same applies to the estimation of attributable deaths, YLLs, and YLDs. The PAF is defined as the proportion of burden due to a cause that occurred because of exposure to a given risk factor-considering the counterfactual level of TMREL, in this case for HSBP [9].

For the production of estimates for risk factors, central estimates (means) with 95\% uncertainty intervals (95\% UIs) were reported. To ensure that UIs capture the uncertainty of all relevant sources (exposures, relative risks (RR), TMRELs, and disease burden estimates), uncertainty was propagated through the analysis. When reported, the percent change estimates were calculated from the central estimates for the time points being compared [9]: the 95\% UI was calculated by performing a percent change calculation of the full set of 1000 draws in order to propagate uncertainty. The percent change of the means was then taken to report the mean percent change, and the 95\% UI were taken from the draw level calculation.

More detailed methodological information is available in the GBD 2017 publication on risk factor-related burden of disease [9].

\section{Estimates for high systolic blood pressure}

The GBD study estimates for HSBP are produced for individuals $\geq 25$ years old. For GBD 2017, 2 new outcomes were added for HSBP: subarachnoid hemorrhage and calcific aortic valve disease, totaling 14 related outcomes (with RRs estimated from published analyses of multiple studies, including a large cohort pooling project [15]): (a) ischemic heart disease, (b) ischemic stroke, (c) hemorrhagic stroke, (d) hypertensive heart disease, (e) cardiomyopathy, (f) atrial fibrillation, (g) aortic aneurysm, (h) rheumatic heart disease, (i) peripheral vascular disease, (j) endocarditis, (k) chronic kidney disease, (l) subarachnoid hemorrhage, (m) calcific aortic valve disease, and (n) other cardiovascular diseases (not listed above). Endocarditis is included due to its association with HSBP in large cohort studies, possibly through the effect of blood pressure on endocarditis-related heart failure. For the outcomes, not only conditions directly resulting from, but also those aggravated by HSBP levels were considered $[9,13]$. The aggregate result included death and morbidity. For each outcome, the age- and sex-specific RRs associated with a measured systolic blood pressure were estimated using the DisMod metaregression tool, considering a TMREL of 110-115 $\mathrm{mmHg}[9,13]$. For this study, prevalence of HSBP considered exclusively the presence of measured $\mathrm{SBP} \geq 140$ $\mathrm{mmHg}$, derived from the continuous GBD estimation of SBP, regardless of the diastolic blood pressure (DBP) or the use of anti-hypertensive drugs.

This analysis was divided into 5 components: (1) distribution of HSBP (prevalence) by age, sex, and location; (2) RRs of the 14 outcomes; (3) determining specific PAF for selected outcomes; (4) estimation of attributable deaths and DALYs, stratified by Brazilian federal units, sex, and group of years; and (5) drivers of trends for morbidity and mortality [9-11].

\section{Metrics of disease burden}

The DALYs combine information regarding premature death (YLLs) and disability caused by the condition (YLDs) to provide a summary measure of the healthy years lost due to the condition. The YLLs were calculated by multiplying the deaths observed at each specific age in a certain year by the reference age-specific life expectancy estimated from life table methods. The YLDs were calculated by multiplying health states resulting from sequelae of diseases caused by HSBP (in number of cases/year) by a health-state-specific disability weight representing a degree of lost functional capacity. The process of estimating the burden of the disability has been previously described in detail $[10,11,14,16]$. The burdens of disability were determined via home interviews in several countries, in which participants were asked to choose between lay descriptions of different health states. For the aggregate of multiple health outcomes attributable to HSBP, adjustment of estimates was performed to account for comorbidity, simulating 40,000 individuals in each age-sexcountry-year stratum exposed to the independent likelihood of developing each condition, based on disease prevalence, with 95\% UI reported for each estimate [11]. Combining disability weights for each simulated individual, this adjustment adds correlations between coexisting diseases to the model. Age-standardization was obtained via the direct method, applying a global age structure [14, 16] (Supplement 1).

\section{Drivers of trends}

A decomposition analysis of changes in DALYs-a modification of the 3-factor Das Gupta decomposition 
$[9,17]$-was undertaken over the time period into 4 main components, due to changes in (1) population growth, (2) population age structure, (3) risk exposure, and (4) all other factors not included in the analysis, the latter termed as the risk-deleted death and DALY rates. Risk-deleted rates refer to age-standardized death and DALY rates expected if all risk factors included in GBD 2017 were removed, estimated as age-standardized DALY rates multiplied by one minus the PAF for the set of risks. The decomposition analysis was performed for each 5-year time period. The contribution of changes in exposure to the individual risks was scaled to the all-risk effect at the most detailed outcome level $[10,11]$.

\section{Sociodemographic index (SDI)}

The SDI-weighted geometric mean of per capita income, schooling level, and fertility rate under the age of 25-from 1990 to 2017 was used as an estimate of the socioeconomic level of each geographic location, aiming to assess its association with the burden of HTN as a function of the global epidemiological transition [18]. Theoretically, SDI ranges from 0 (lowest) to 1 (highest) and, among countries included in GBD, varies from 0.19 (South Sudan) to 0.94 (Luxembourg).

This study is based on the GBD 2017 data and analytic methods, as described previously in detail [9-11], and on the methodology for data collection and adjustment techniques, as described above. Data were analyzed for the period from 1990 to 2017. All analyses were stratified by sex and presented as absolute and agestandardized estimates for the different FUs of the Brazilian territory, in addition to a comparison of the estimates from Brazil with those of the BRICS countries (Brazil, Russia, India, China, and South Africa) and other countries with universal healthcare (Canada and England), for a better global contextualization of the estimates. Some analyses were further stratified by SDI.

\section{Ethical considerations}

The GBD study was approved by the Institutional Review Board of the University of Washington. There was no need to submit to this research to the local Institutional Review Boards, as the study was conducted in a public domain secondary database, without nominal identification, in accordance with Decree No. 7,724, May 16, 2012, and Resolution 510, of April 7, 2016. The GBD Brazil study was approved by the Institutional Review Board of the Universidade Federal de Minas Gerais, under the protocol CAAE - 62803316.7.0000.5149.

\section{Results}

\section{Prevalence of HSBP}

Table 1 shows the age-standardized prevalence of HSBP in Brazil, which increased from 1990 to 2017, from
$16.9 \%$ (95\%UI 16.5 to $17.3 \%$ ) to $18.9 \%$ (95\%UI 18.5 to $19.3 \%)$, being higher in men than women along the whole period (Fig. 1a). Although its annualized rate of change is still positive $0.4 \%$ (95\% UI 0.3 to $0.5 \%$ ), Fig. 1a reveals that the rise in prevalence rates are declining across the years. If the rates evaluated are not standardized for age, the increase in prevalence is higher (Table 1 and Fig. 1b), due to population aging. Crude and agestandardized prevalence rates and annualized percent change for each federal unit, for both sexes and stratified by sex, are shown in Table 1.

\section{Mortality and morbidity attributed to HSBP}

Figure 2a shows that HSBP is the leading risk factor for the total number of deaths in Brazil and has risen from 3rd in 1990 to 1 st position in 2017. During the period, the total number of deaths attributable to HSBP increased $53.4 \%$ (95\% UI 50.0 to $57.4 \%$ ) (Table 2), accounting for 150,250 (95\% UI 135,714 to 164,122$)$ deaths in 1990 and 230,454 (95\% UI 209,698 to 251,499) in 2017. Regarding DALY, HSBP has also gained importance rising from 4th to 2nd position from 1990 to 2017-only behind smoking (Fig. 2b). The leading role of HSBP as a risk factor for death is for both sexes and results from deaths due to cardiovascular and chronic kidney diseases (Fig. 3).

When evaluating the age-standardized death rate attributable to HSBP in Brazil, it has fallen 44.6\% (95\% UI 42.9 to $45.9 \%$ ), from 189.2 (95\% UI 168.5 to 209.2 ) deaths to 104.8 (95\% UI 94.9 to 114.4 ) deaths per 100 , 000 from 1990 to 2017. Comparing to other countries with similar development stage, such as other countries from the BRICS group (Brazil, Russia, India, China, and South Africa), Brazil has reduced the all-cause deaths attributed to HSBP from 2nd to the 5th and least position of the group from 1990 to 2017, although the rate of deaths attributed to HSBP in the country are still higher than other countries with universal healthcare, such as Canada and England, shown for comparison (Fig. 4).

Table 2 shows the all age deaths and DALYs, in 1990 and 2017, and percent change of deaths and agestandardized death rates, DALYs, and age-standardized DALY rates between 1990 and 2017 attributable to high blood pressure in Brazil and its FUs.

\section{Causes of deaths and DALYs attributable to HSBP}

Regarding the leading causes of death attributable to HSBP, ischemic heart disease is in the 1st position, followed by stroke (Additional file 2). While the deaths and DALY due to the main causes of death attributable to HSBP are decreasing, deaths due to peripheral artery disease, atrial fibrillation, and aortic aneurysm are rising. Figure 5 shows that they are similar across federal units. Hypertensive heart disease and chronic kidney disease 


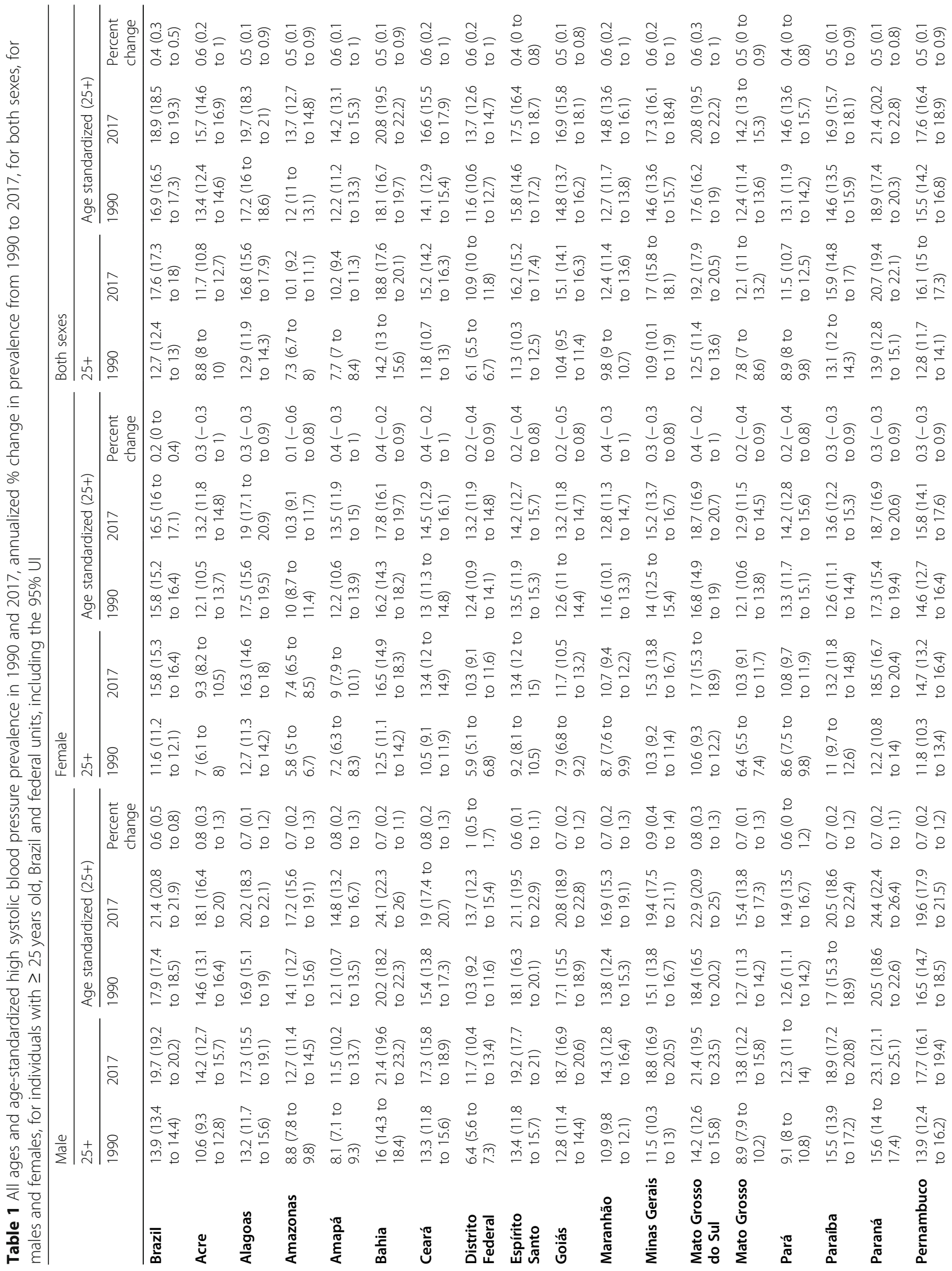




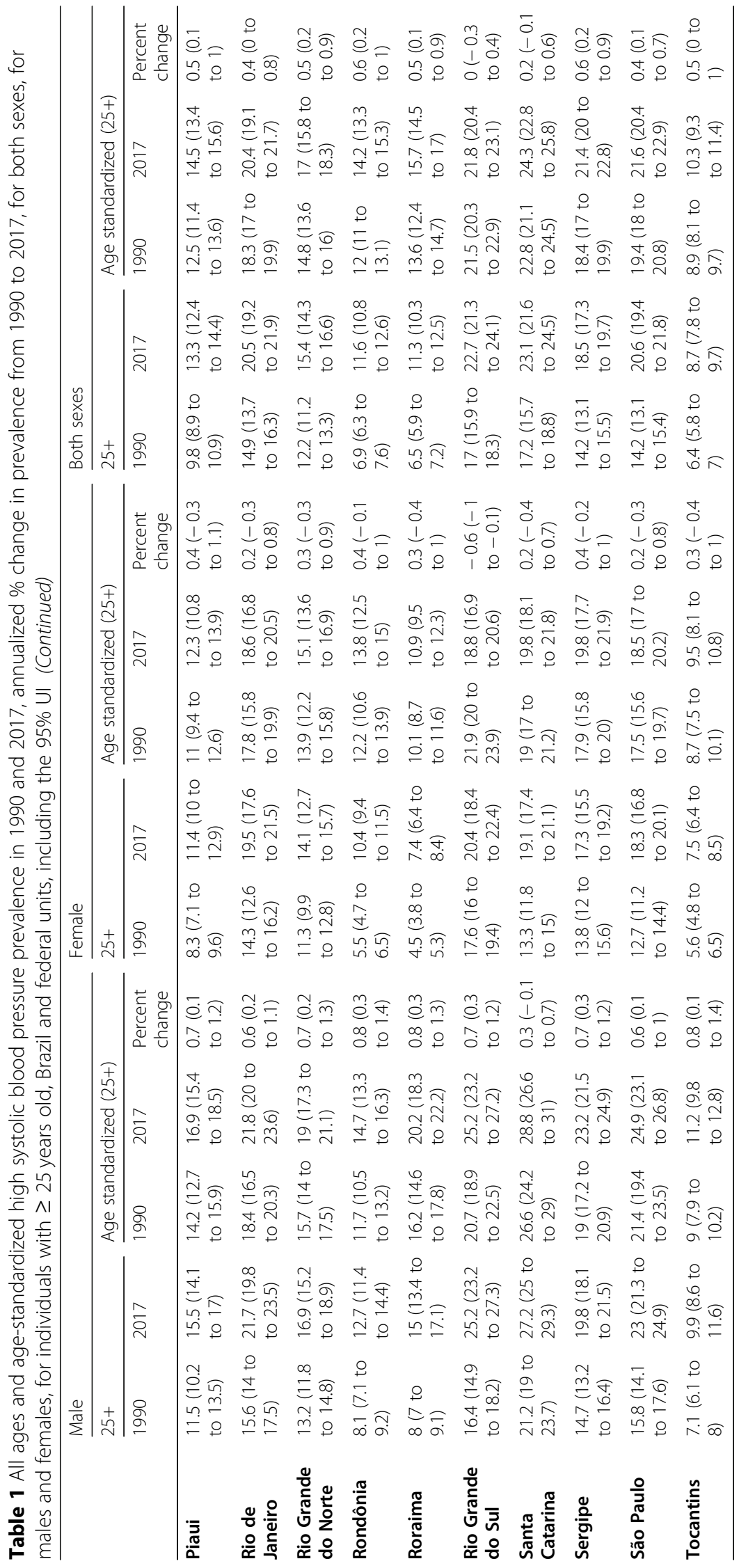


Prevalence of high blood pressure ( $>140)$, Brazil age-standardized (25+)

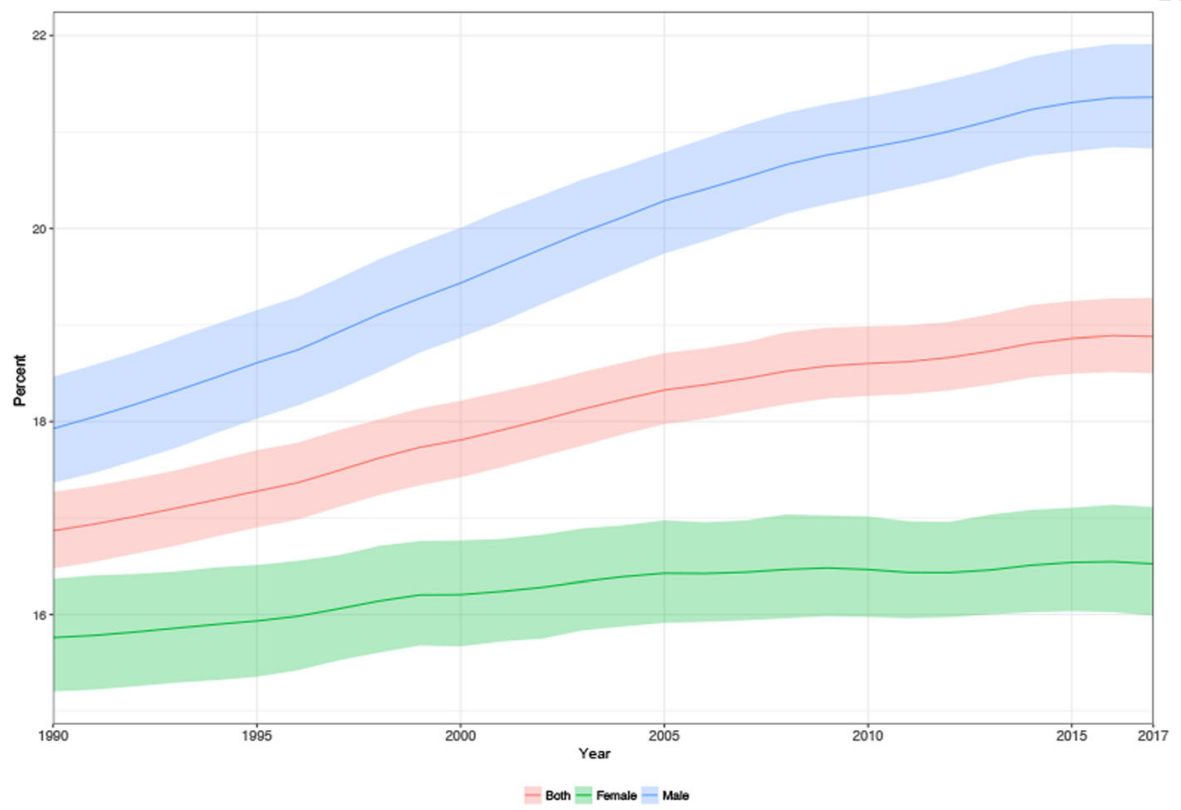

B

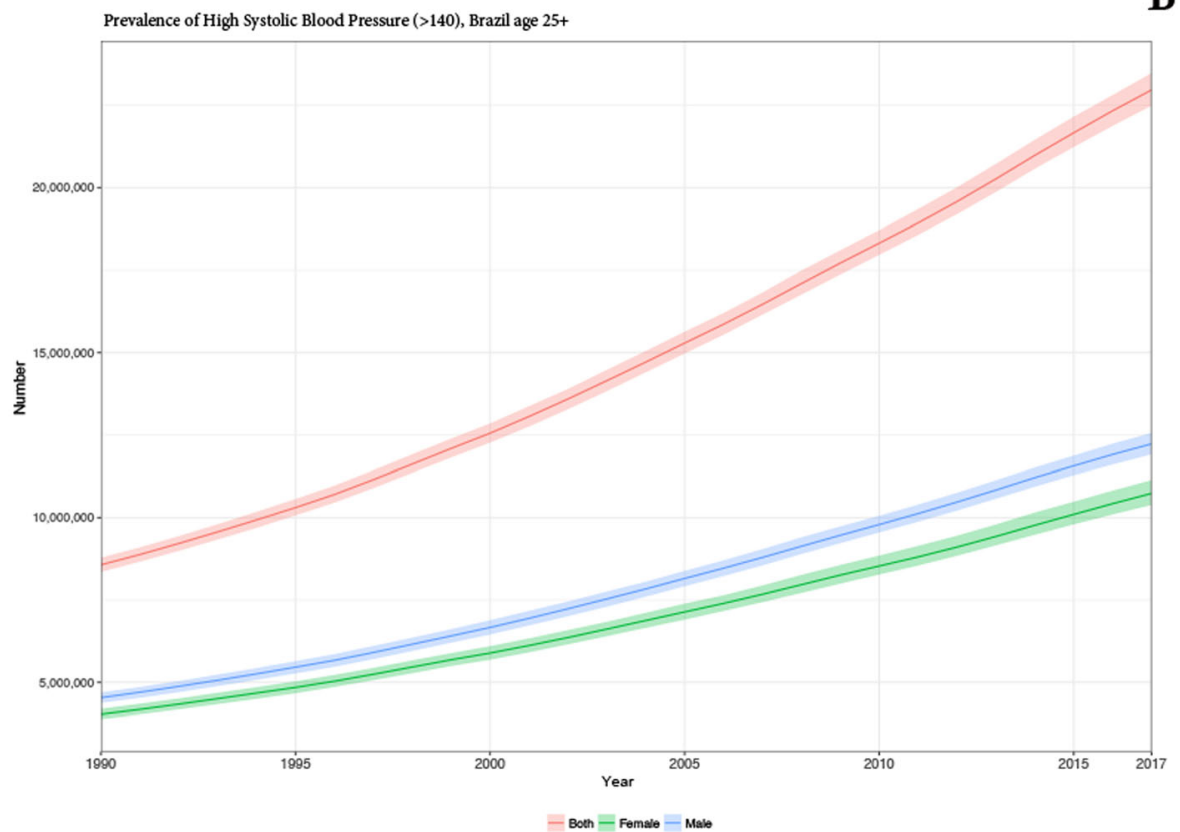

Fig. 1 Trends in prevalence of high systolic blood pressure in Brazil for men, women, and both sexes for individuals with $\geq 25$ years old, 1990 2017. a Age-standardized prevalence. b Total number

alternate in the 3rd and 4th position depending on the federal unit.

Additional file 2 demonstrates all age deaths and DALYs in 1990 and 2017 and percent change of deaths and agestandardized death rates, DALYs, and age-standardized DALY attributable to HSBP, for cardiovascular diseases, for both sexes and stratified by sex, in Brazil. Figure 6 demonstrates the main causes of deaths and DALY attributable to HSBP across Brazilian federal units.
A

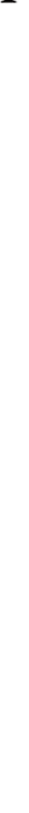




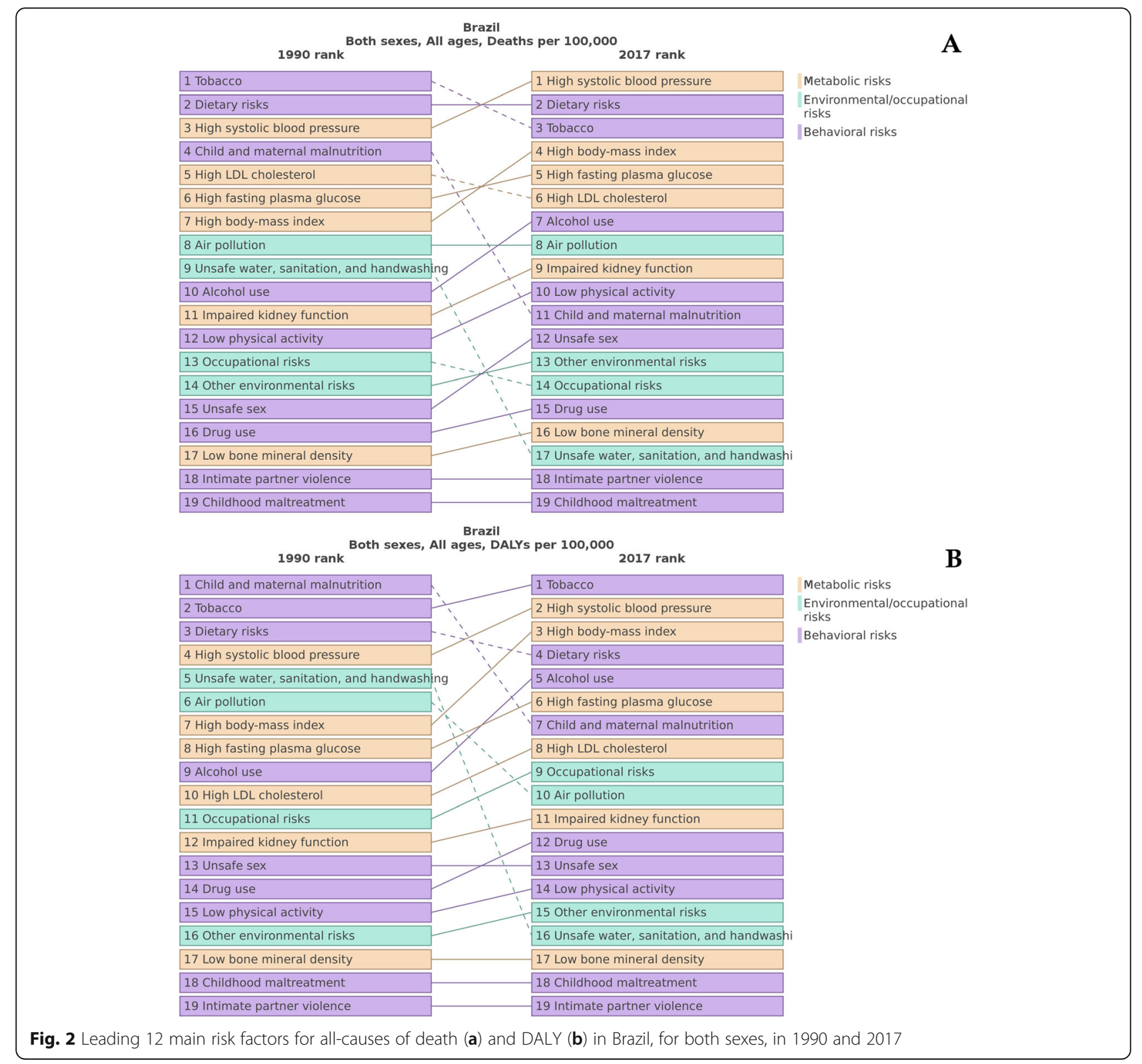

but were offset by increases due to the other factors (population aging, growth, and risk exposure) (Fig. 7).

\section{Correlation of death and DALY rates attributable to HSBP to SDI}

Figure $8 \mathrm{a}, \mathrm{b}$ reveals that the reduction in the all-cause age-standardized death rates attributable to HSBP is heterogeneous across federal units. For example, in Ceará, the death rate reduced from 97.3 (95\% UI 83.6 to 112.0 ) per 100,000 in 1990 to 81.3 (95\% UI 71.7 to 90.5 ) per 100,000 in 2017 (16.5\% [95\% UI 8.9 to $23.3 \%$ ] decrease), while in Espírito Santo the change was from 219.7 (95\% UI 192.5 to 245.8 ) per 100,000 in 1990 to 99.8 (95\% UI 90.4 to 109.2$)$ per 100,000 in 2017 (54.6\% [95\% UI 51.9 to $57.1 \%$ ] decrease). Figure $8 \mathrm{a}$ demonstrates the correlation between age-standardized death rates attributable to HSBP and the 2017 SDI. We found a moderate positive correlation $(r=0.61)$ in 1990 that was not maintained in $2017(r=-0.08)$. Figure 8b shows that the percent change in death rates attributable to HSBP between 1990 and 2017 was strongly and negatively correlated to the SDI in 2017 ( $r=-0.77)$.

Regarding age-standardized DALY rates attributable to HSBP, a similar pattern was observed. The moderate positive correlation found between it and SDI $(r=0.51)$ in 1990 was also not maintained in 2017 and became negative $(r=-0.22)$ (Fig. 9a), and the percent change in DALY rates attributable to HSBP between 1990 and 2017 was negatively correlated to the SDI $(r=-0.75)$ (Fig. 9b). 


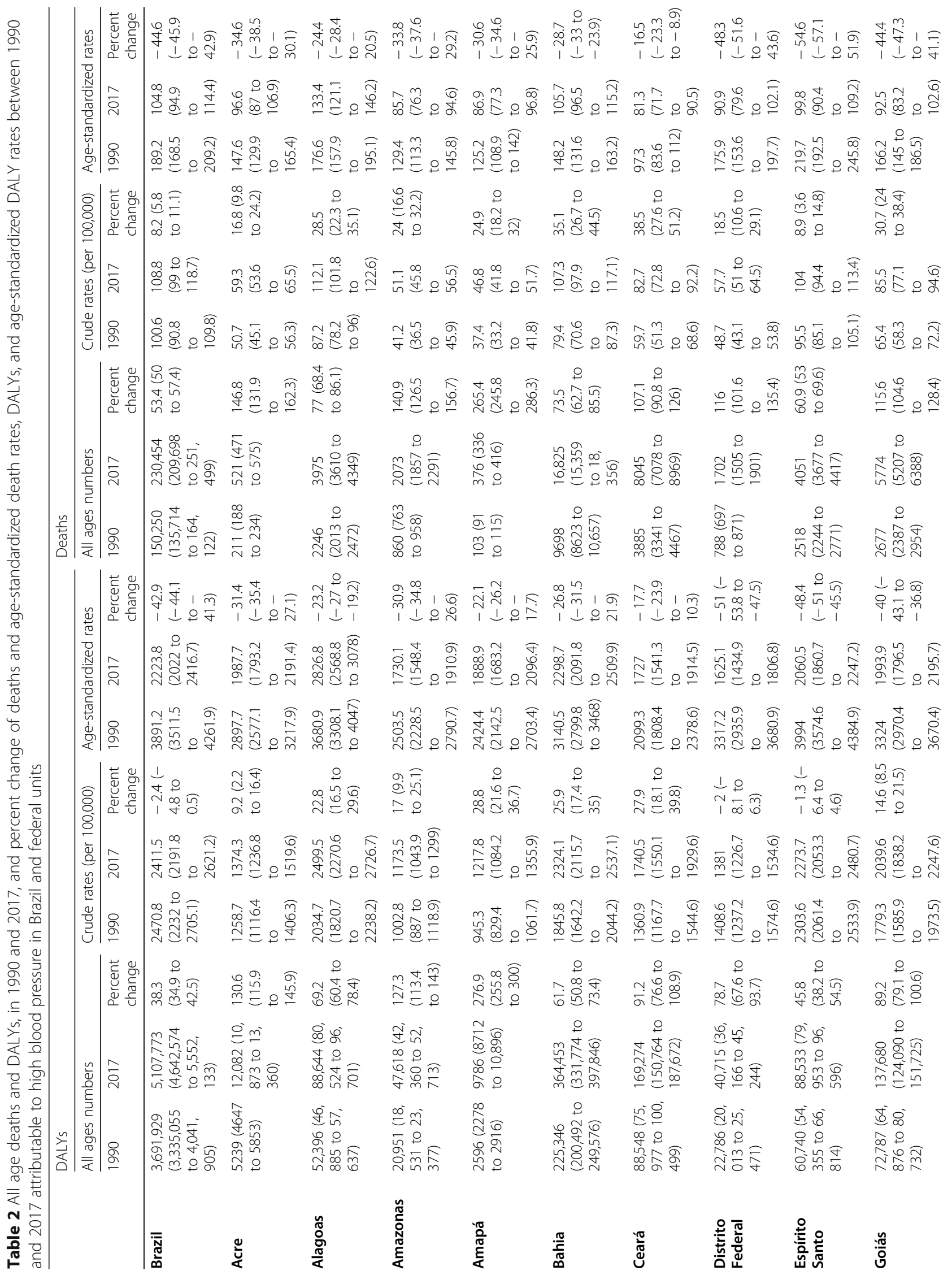




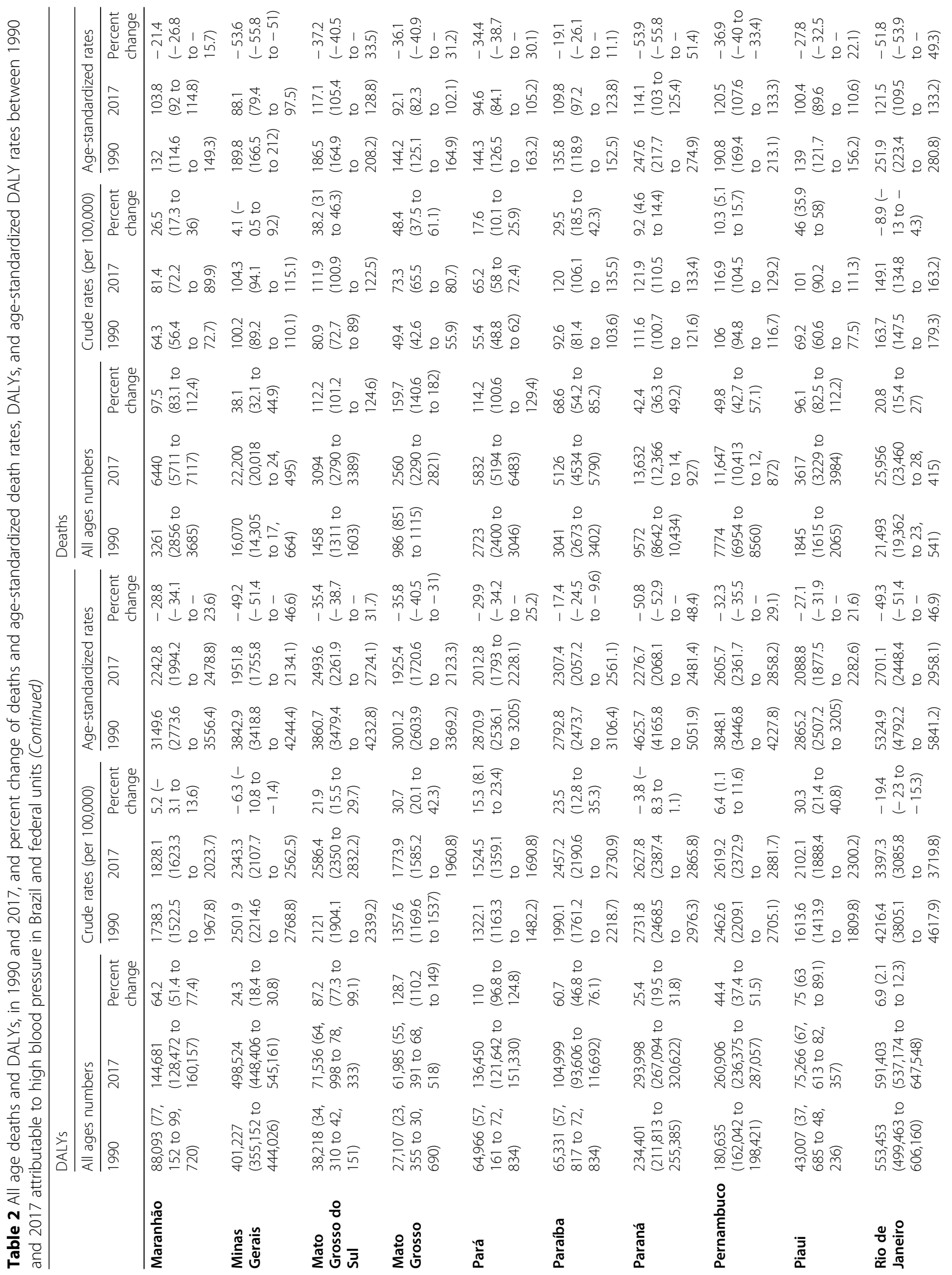




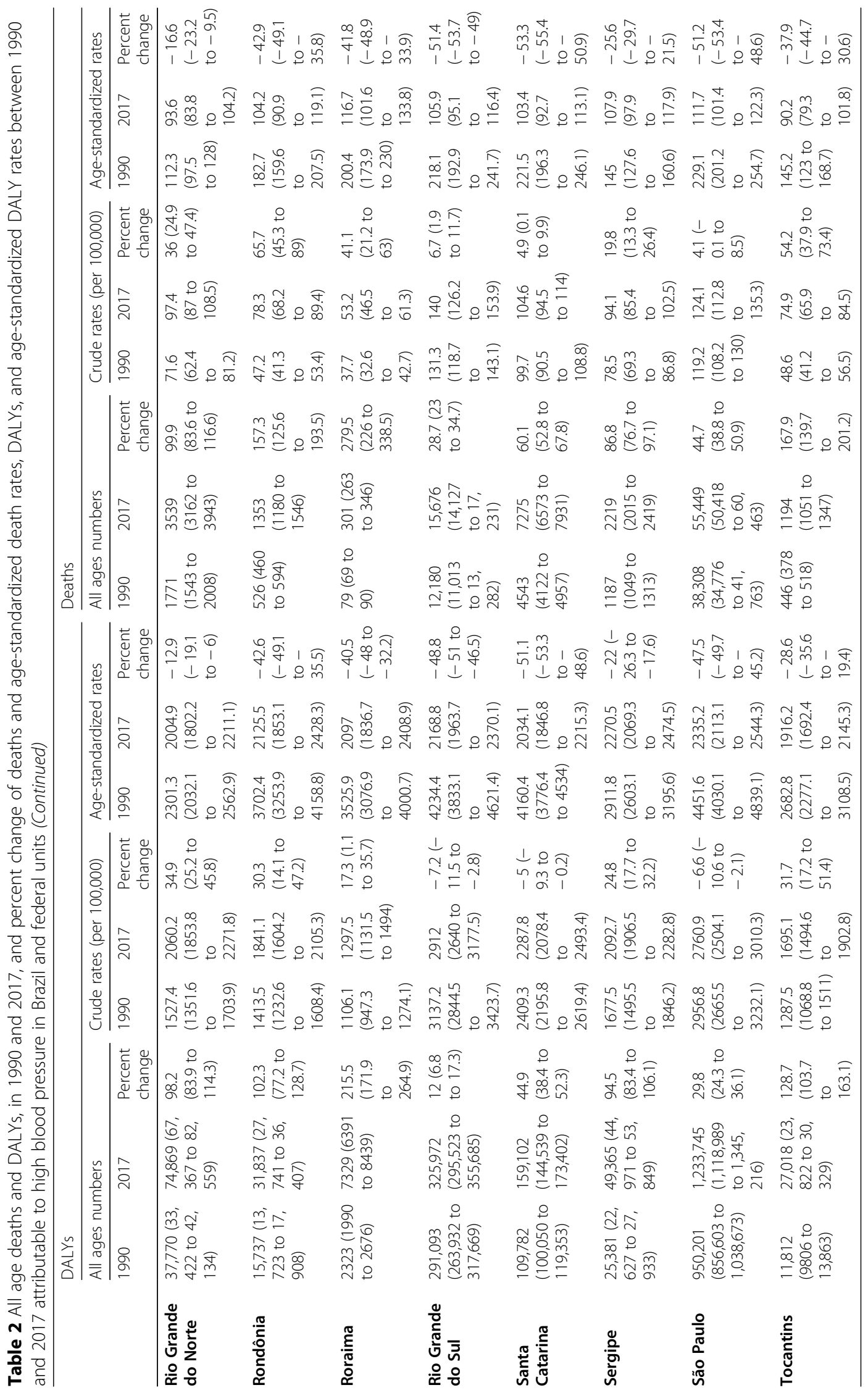




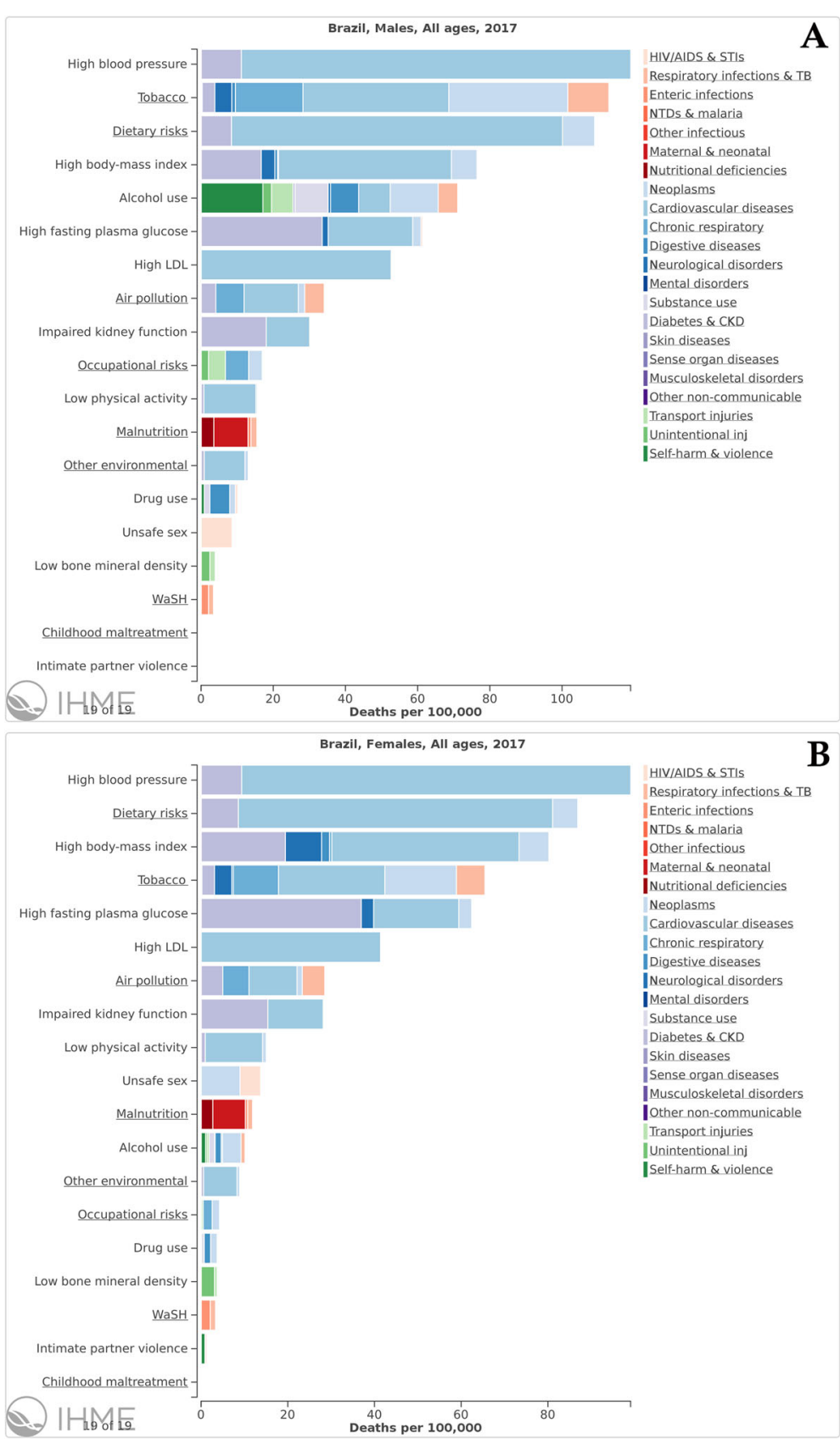

Fig. 3 Attributable risk of 17 main risk factors for all-causes of death in Brazil, stratified by sex, in 2017

\section{Discussion}

HTN is a risk factor for CVD, especially for cerebrovascular diseases, ischemic heart disease, and chronic kidney disease, and its recognition and control should be emphasized, in order to reduce the burden of its associated conditions. In our analysis, from 1990 to 2017, there was an annual (0.4\%) increase-with an almost stable behavior in more recent years-in the agestandardized prevalence of HSBP, currently the leading risk factor for death in Brazil. Although the age- standardized death and DALY rates due to HSBP are declining in Brazil, possibly as a result of successful health policies, the total number of deaths and DALY are increasing mainly due to population aging. Moreover, the reduction in age-standardized death and DALY rates are heterogeneous across $\mathrm{FU}$, being more pronounced in the more developed FU.

Several factors, including sociodemographic, ethnical, cultural, dietary, and behavioral issues, may account for the differences in the burden of HSBP between 


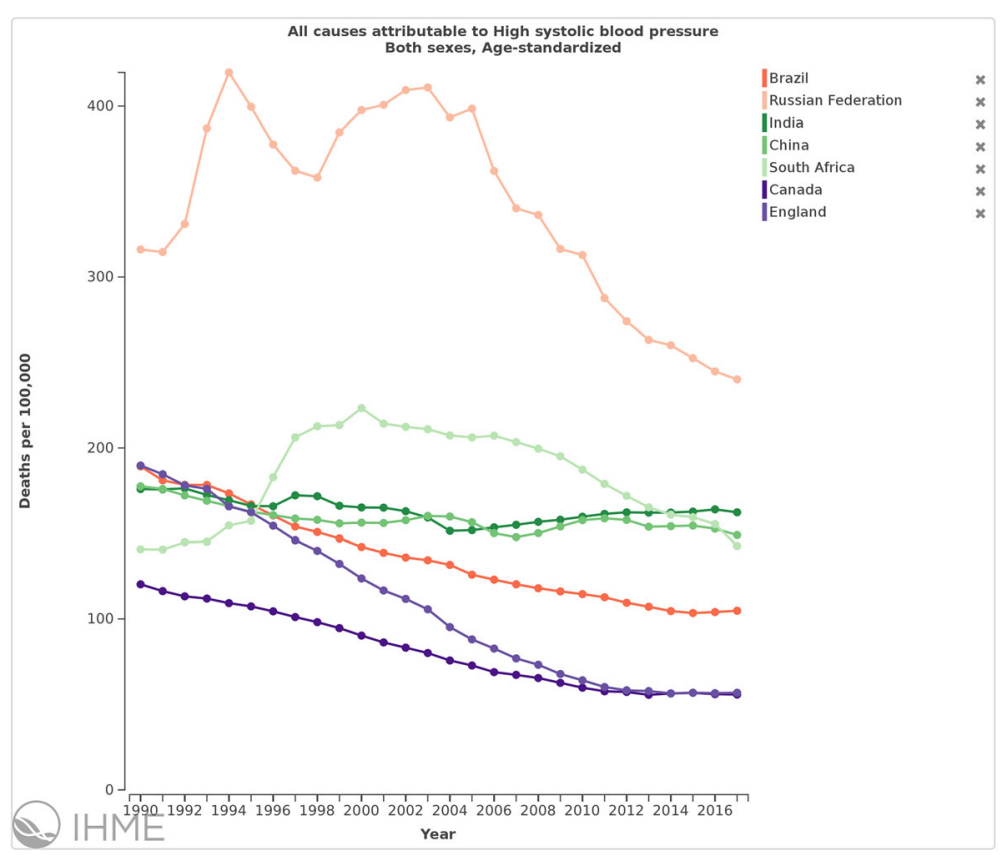

Fig. 4 Trends in all causes of deaths attributable to high systolic blood pressure in Brazil, Russia, India, China, and South Africa (BRICS), Canada, and England, both sexes and age standardized, 1990-2017

populations and also for the trends over decades. Global prevalence estimates may also vary according to the methodology applied. The pooled age-standardized prevalence of HSBP or high DBP in 200 countries was estimated at $24.1 \%$ (95\% UI 21.4 to $27.1 \%$ ) in males and $20.1 \%$ (95\% UI 17.8 to $22.5 \%$ ) in females in 2015 , with the authors underscoring the decline observed in Latin America between the 1970s and 2015, although Brazil was not specifically mentioned [19]. In the GBD study, involving 195 countries, the estimated global prevalence of HSBP was $17.1 \%$ in $2017[9,11]$.

Several studies have been conducted on the prevalence of HTN in Brazilians cities and regions in the last decades, although there is substantial variability of definitions and methodology $[1,10]$. Concerning country-wide studies, the Brazilian Health Ministry has been conducting, since 2006, a yearly telephonic survey in FU capitals for chronic diseases and risk factors, the VIGITEL, with a question about medical diagnosis of hypertension [20, 21]. More recently, in 2013, direct blood pressure measurements, as well as the information about the use of anti-hypertensive drugs, were incorporated [3]. The addition of these data to GBD was crucial, as it brings more realistic information regarding the profile of the population with HTN. The prevalence of HSBP by GBD estimates in Brazil, however, cannot be directly compared to previous studies, considering methodological particularities of the GBD model, in which prevalence is derived from a continuous distribution of systolic blood pressure (with $\mathrm{a} \geq 140 \mathrm{mmHg}$ threshold in this analysis), and patients with isolated diastolic HTN or those controlled by antihypertensives are not included [9]. This concern is even more compelling in regions with moderate to good access to medications, where patients under treatment with SBP levels below $140 \mathrm{mmHg}$ will not meet the cutoff derived from the GBD continuous estimation of systolic BP. Most previous population-based studies $[1,8,10]$ used as the diagnostic criteria the presence of blood pressure (BP) $\geq 140 / 90 \mathrm{mmHg}$ or the use of BP lowering medication, which necessarily led to a higher prevalence than observed in GBD. Indeed, a meta-analysis from 2012 showed a mean prevalence of HTN of $28.7 \%(26.2-31.4 \%)$ for decade of $2000 \mathrm{~s}$ [22], while the National Health Survey 2013 (adults > 18 years old) showed a general prevalence of $32.3 \%$ considering direct measurement and/or reported use of medication, contrasting with $21.4 \%$ for selfreporting and $22.8 \%$ for measured HTN [3]. For the burden estimates, the above concern is not applied, because HSBP was considered as exposure above a TMREL of $110-115 \mathrm{mmHg}$. However, for the purpose of estimating disease burden attributable to HSBP, the GBD method of estimating the full distribution of SBP regardless of medication use seems to be the best approach, as a continuous exposure measure takes into account the nuance of different risks for the different levels of BP.

Analyzing our results stratified by sex, it should be noted that the prevalence was overall higher among men during the study period, following a classical trend of 

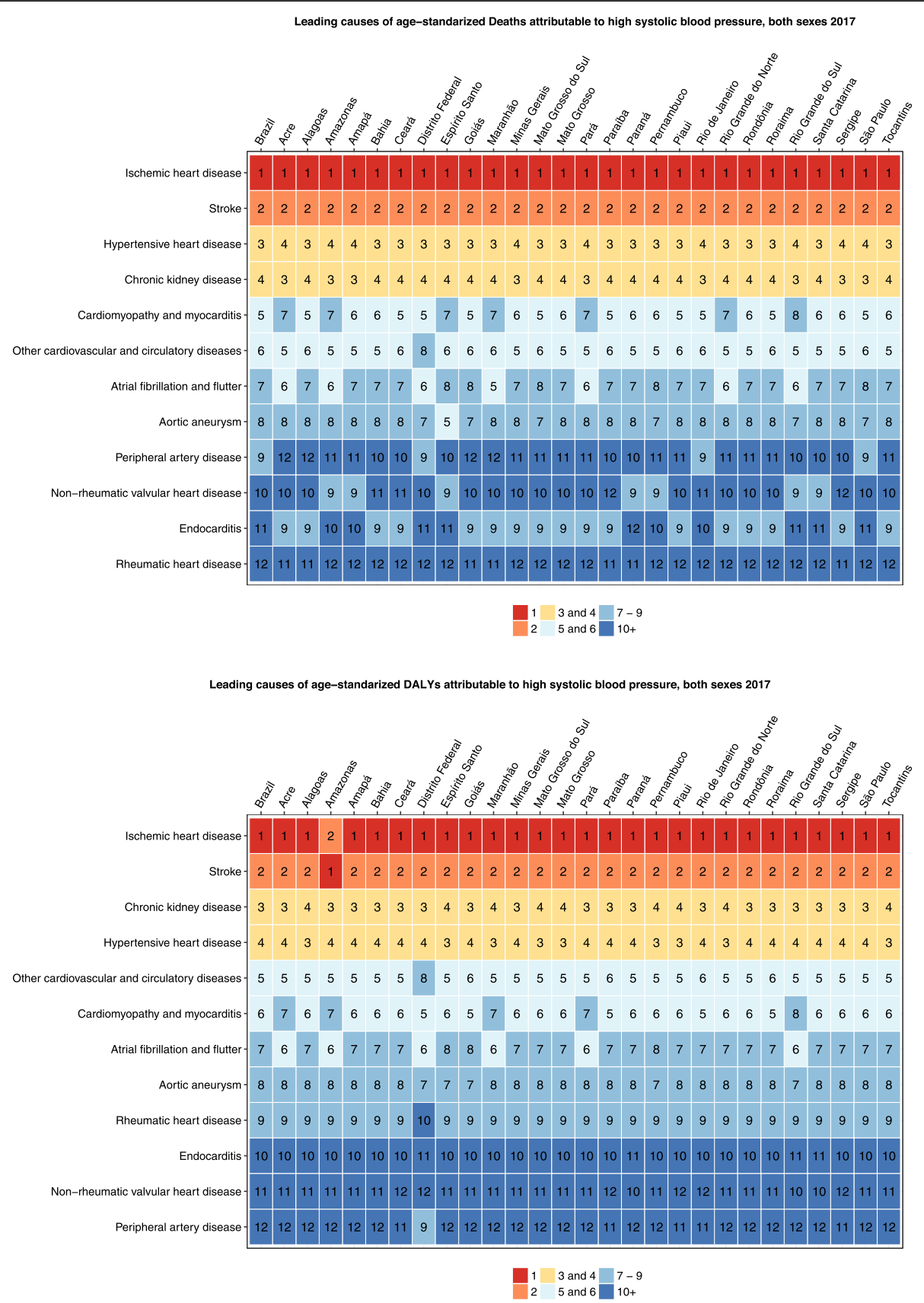

Fig. 5 Main causes of deaths (a) and DALYs (b) attributable to high systolic blood pressure, both sexes, Brazilian federal units, 2017

HTN [13], despite the growing similarities of health behaviors between sexes in the past decades [23]. Besides biological determinants, such as estrogen protection, several other complex cultural, environmental, behavioral, and healthcare access factors may be implicated in this difference by sex. Higher prevalence of HSBP in men differs from the HTN prevalence estimated by selfreported population surveys [21] which tend to overestimate prevalence in women, whom are generally more adherent to medical services.
The small percent increase in age-standardized prevalence observed in Brazil-especially in men-was relatively homogeneous across the FUs. Of note, only in Rio Grande do Sul and Santa Catarina, there was no variation or even a slight reduction trend in this period, considering the UIs. In the VIGITEL telephone survey, the prevalence of self-reported medical diagnosis of HTN did not change from 2006 to 2017 [20] - but a non-significant increasing trend in the past years was observed-while a previous meta-analysis of population- 


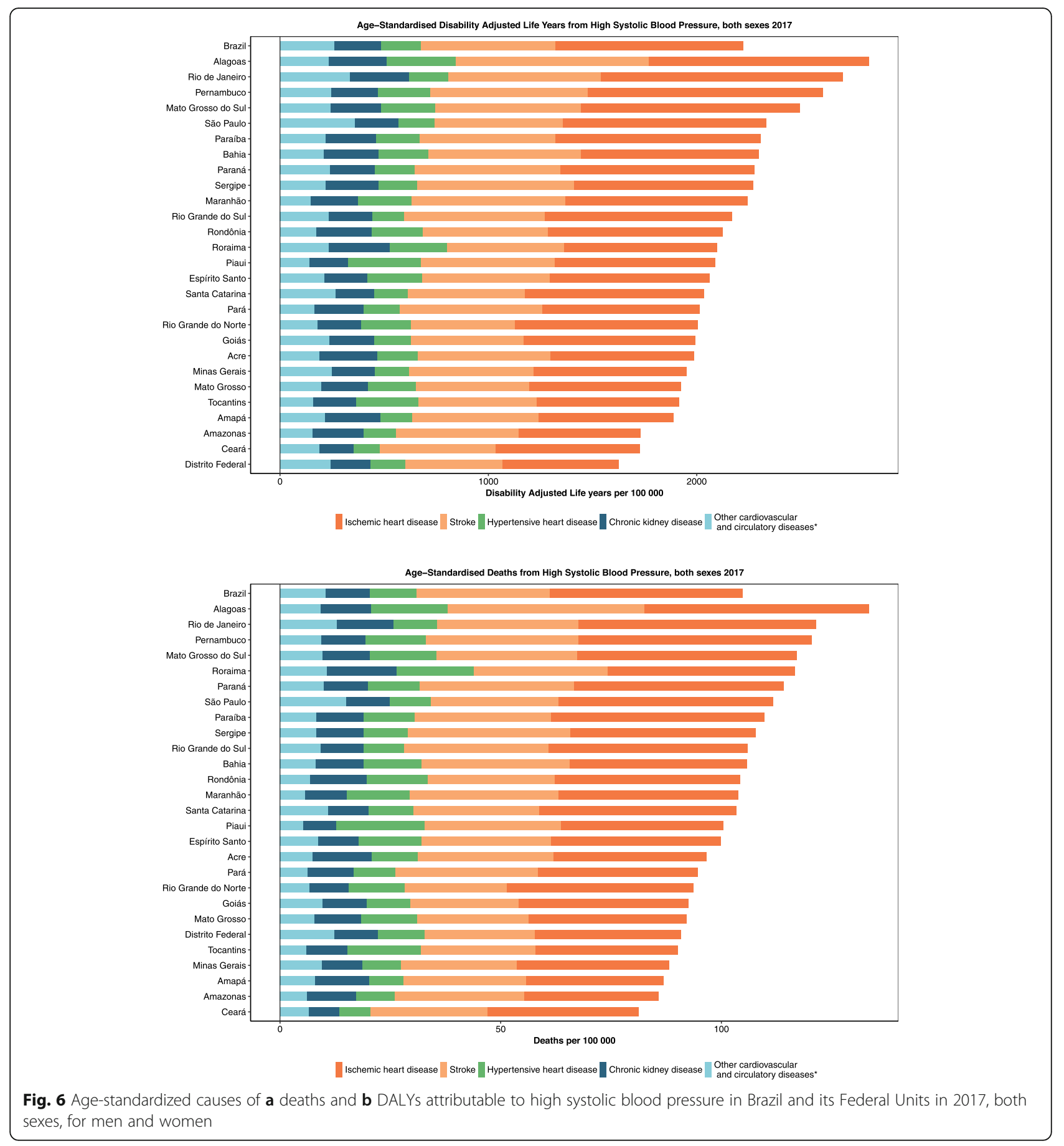

based studies showed a trend toward decreasing prevalence from 1987 to 2007 [8]. Considering the limitation of all sources of data for evaluating this discordance, only a new National Health Survey, planned to be conducted in 2019, will be able to give a definite response for this question. However, other related risk factors, such as obesity [24] and diabetes [25], have already increased in prevalence during the same period, suggesting there is room for health promotion and prevention strategies that could lead to a better control of cardiovascular risk factors in Brazil. Also, considering the GBD methodology, HSBP can be understood as undetected or inadequately treated HTN, and the stable-to-growing trend observed in our analysis may be mainly linked to unsuccessful treatment. In this scenario, greater access to home measurement and better efficacy of selfmanagement programs-including new technology for remote medical advice-may improve $\mathrm{BP}$ control. 

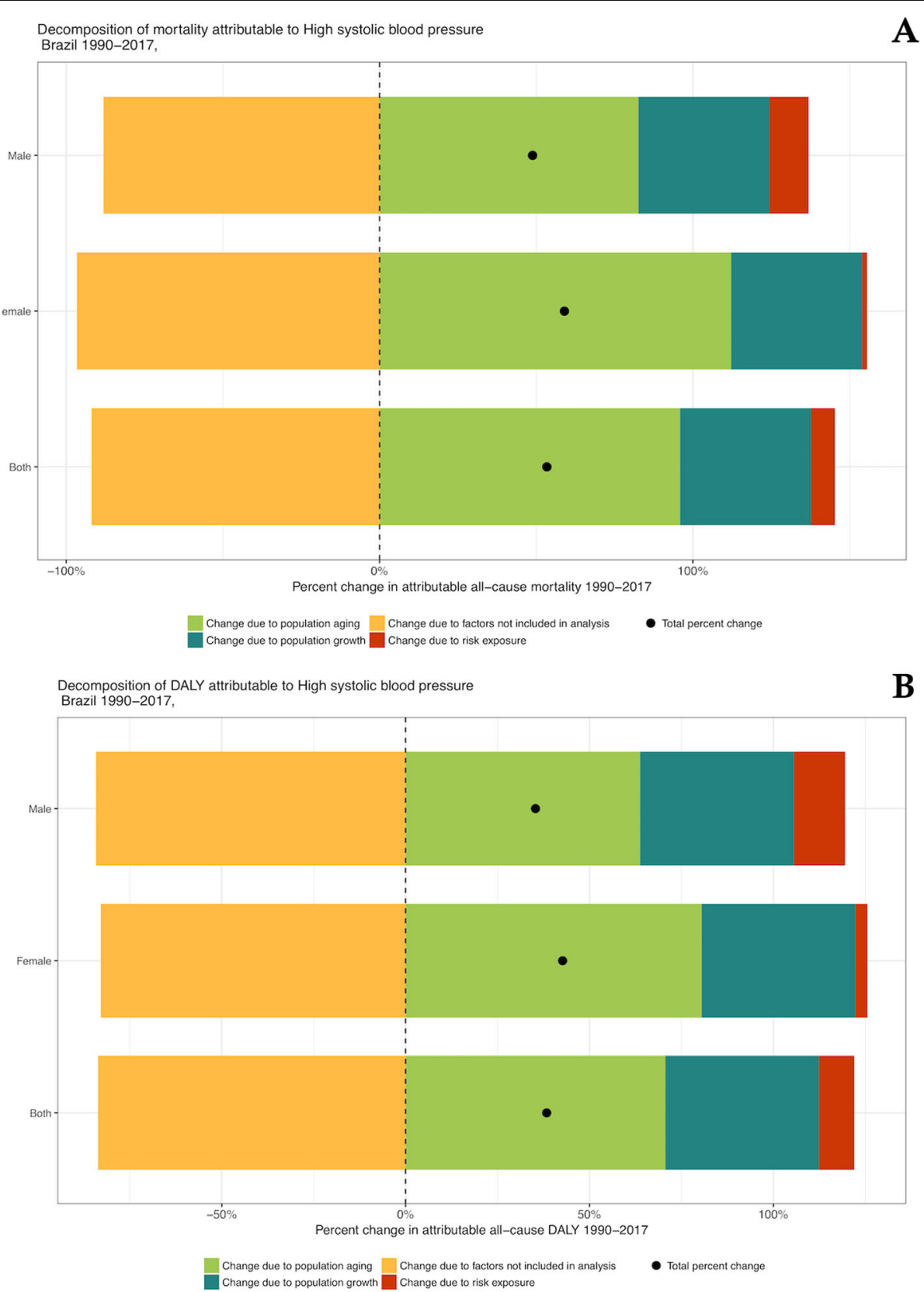

Fig. 7 Percent change in deaths (a) and DALYs (b) attributable to high systolic blood pressure in Brazil, 1990-2016, due to population growth, population aging, trends in exposure included in GBD 2016, and all other (risk-deleted or residual) factors

Despite the observed slight growth of HSBP prevalence, the trends in the burden attributable to HSBP in Brazil, with decreasing age-standardized rates, suggest that efficient health policies for CVD control were implemented in the period. The increase in total numbers of deaths and DALY attributable to HSBP depict the effect of population aging and growth in the country. To analyze the drivers of the abovementioned trends is essential for health policy planning [26]. The relative contributions of population aging reflect life expectancy at birth that increased continuously from 1950 to 2017, to 72 years for men and 79 years for women. In Brazil, this was mainly due to the decline in under- 5 mortality, with a still high mortality among young adult men driven by interpersonal violence [27]. The relatively small change due to risk exposure observed predominately in men could be attributed to the combined effect of birth cohorts' improvements and treatment of cardiovascular and cardiometabolic diseases, which results in the decrease of CVD and increase in IHD [26]. This can be 

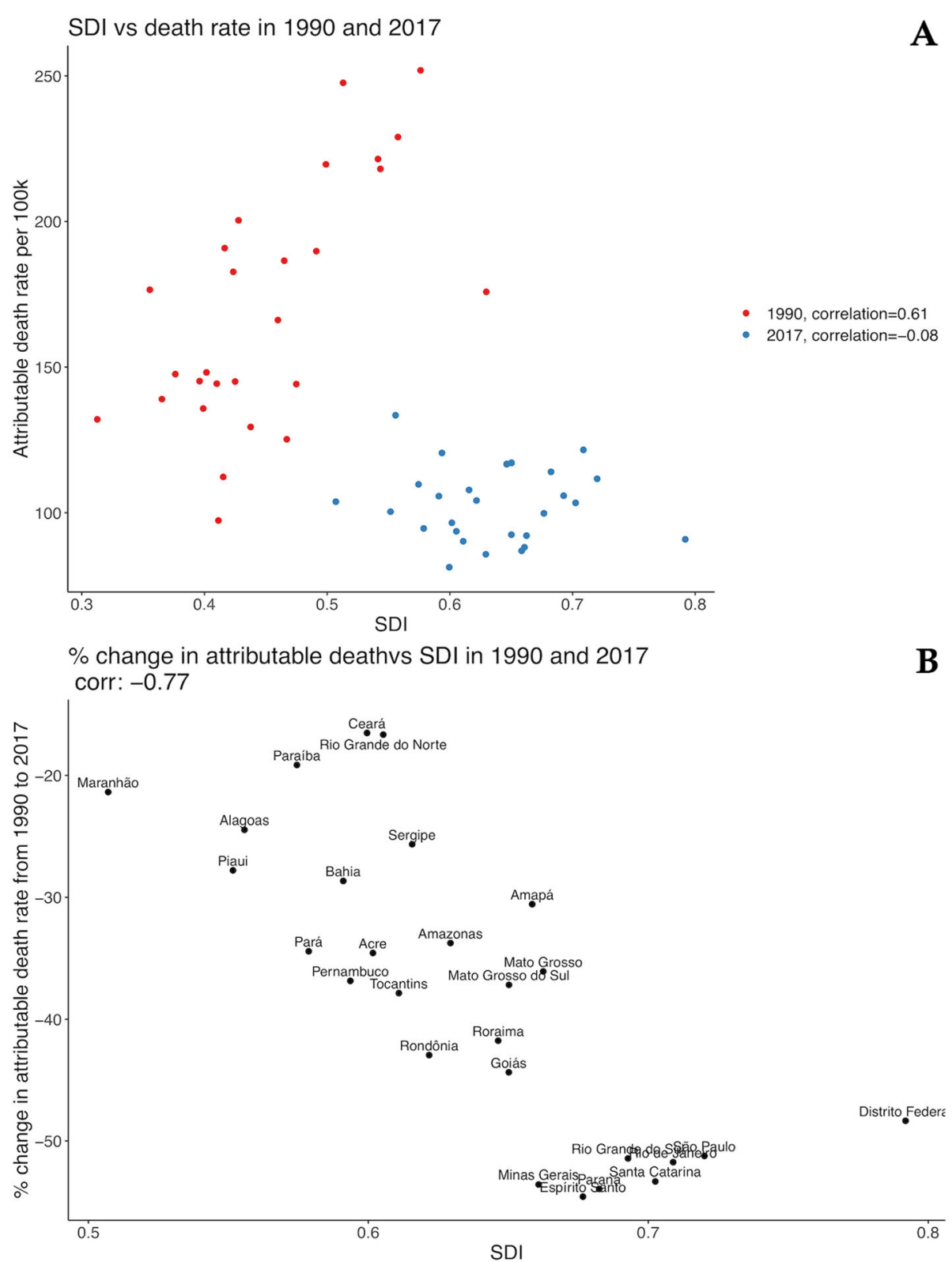

Fig. 8 Correlation between age-standardized death rates attributable to high systolic blood pressure and the 2017 sociodemographic index (SDI) in 1990 and 2017 for both sexes, in Brazilian federal units (a) and percent change in death rates attributable to HSBP between 1990 and 2017 (b)

also interpreted as a tradeoff between worsening determinants of HTN-especially age-versus better healthcare. Conversely, the negative trend of "other causes" (not included in the analysis) is debatable and may also reflect healthcare and other unmeasured factors-as population awareness, etc. - or be a result of improving certainty around measurement in more recent years. A scenario mainly driven by the rapid change in age composition urges health systems to develop long-term action plans for improving primary prevention and sustainable patient-centered educational programs for healthy aging.
In comparison to other BRICS countries, the mortality rate per 100,000 inhabitants attributable to HSBP between 1990 and 2017 decreased 45\% in Brazil and 24\% in Russia, while it practically did not change in the other countries-with even an increasing trend in South Africa-over the period. This finding also suggests the relative efficiency of the large-scale health policies implemented in the country for HTN control, such as established follow-up protocols and multidisciplinary approach for HTN care in the primary health setting, along with free access to antihypertensives [6, 8]. However, among other countries with universal access to health 

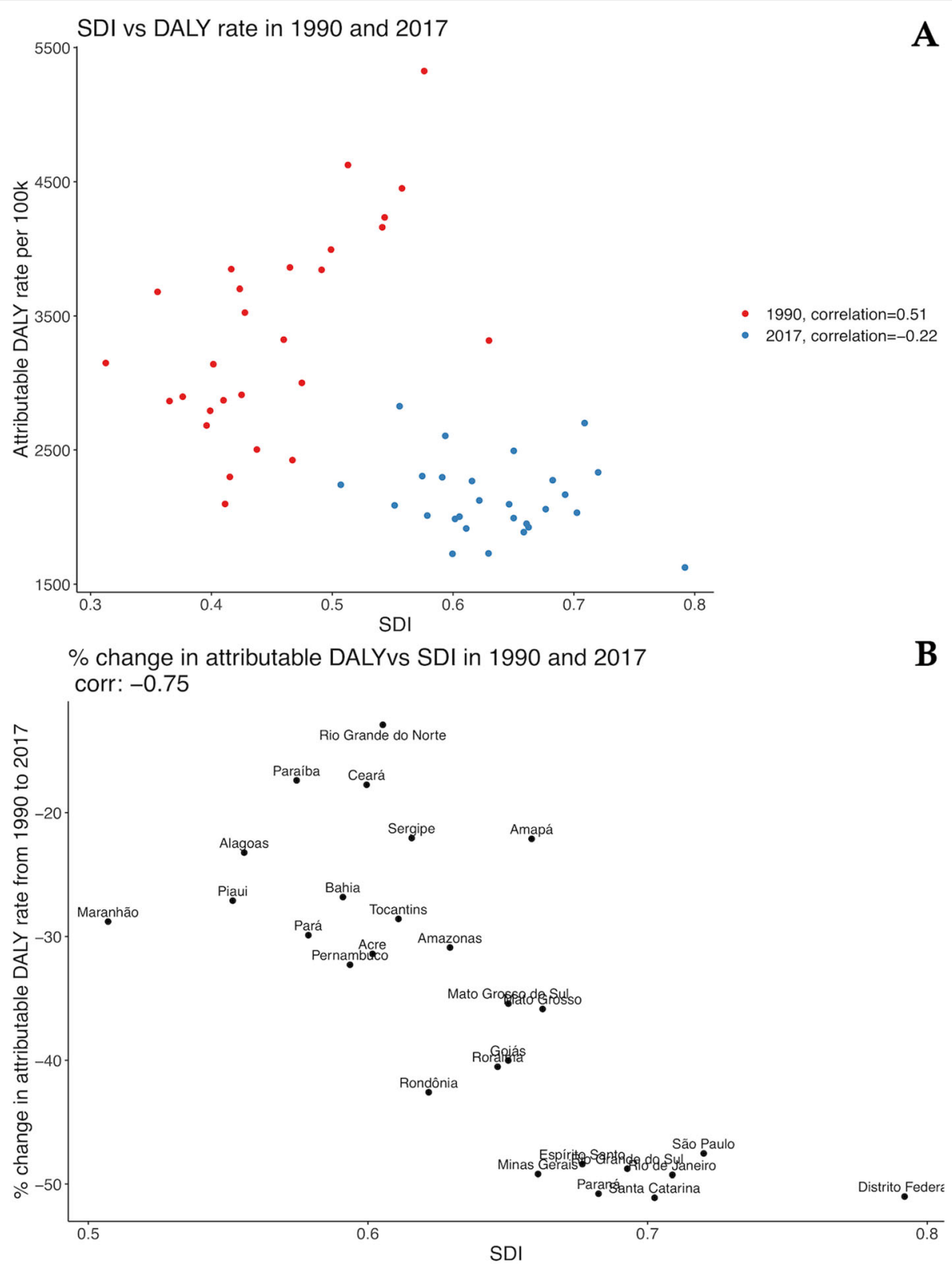

Fig. 9 Correlation between age-standardized DALY rates attributable to high systolic blood pressure and sociodemographic index (SDI) in 1990 and 2017 for both sexes, in Brazilian federal units (a) and percent change in DALY rates attributable to HSBP between 1990 and 2017 (b)

such as Canada and England, we find attributable mortality rates to be about half those observed in Brazil in 2017. Notably, England and Brazil had comparable attributable mortality rates in 1990, indicating that even greater prevention of burden due to HTN may be possible in Brazil. The 2011 Brazilian plan to confront the non-communicable diseases (NCDs) [28], consonant with the World Health Organization (WHO) Action Plan [29] and the United Nations 2030 Sustainable Development Goals [30], emphasizes, among other approaches aiming a $25 \%$ reduction of NCD-associated mortality by 2025 , the control of HTN and many of its determinants. However, considering the stable trend of prevalence and the absolute burden, the results are still suboptimal. One of the reasons for this may be that greater healthcare, medication access, and public policies to prevent CVD are being counterbalanced by unsuccessful approaches to control the determinants of HTN, such as overweight, alcohol intake, and physical inactivity.

It is interesting that prevalence varied considerably among FUs, which may be partially explained by different stages of the epidemiological transition across the country. Age-standardized death and DALY rates were 
higher in FUs with higher SDI in 1990, and the greatest reduction in burden was observed in these locations. In fact, considering the SDI as a proxy for socioeconomic development, the strong positive correlation observed in 1990 contrasts with the absence of significant correlation in 2017, revealing that greater sociodemographic development was associated with the reduction in the burden attributable to HSBP in Brazil. This is supported by the strong negative correlation between the percent changes in death and DALY rates attributable to HSBP between 1990 and 2017 and the 2017 SDI. The relation of socioeconomic development and disease burden in Brazil has already been observed: significantly negative correlation coefficients between the municipal HDI (an index that similarly reflects local development) in 2000 and 2013 and mortality rates for CVD and hypertensive diseases in the state of Rio de Janeiro have been reported [31]. Higher socioeconomic development may be associated with greater awareness about the effects of HTN and better access to healthcare, such as public and private programs related to education, diet, behaviors, and risk factors' control over the period evaluated. Moreover, the improvement in socioeconomic conditions of the Brazilian FUs-while in 1990 the lowest SDI was 0.31 in Maranhão, in 2017 it was 0.51 -and the consequent reduction in socioeconomic gap between FU in Brazil from 1990 and 2017 may have contributed to reduce the magnitude of the statistical correlation with disease burden. According to the United Nations Organizations definition, about $50 \%$ of the Brazilian FU reached a high Human Development Index (HDI) ( $\geq 0.7$ ) by the 2010 decade, explaining the decreasing power of this association [32] and highlighting the health burden posed by socioeconomic disparities. In Brazilian case, the reduction of the HTN burden clearly followed social development. These observations follow a global trend of linear increase of HSBP burden and SDI in places with low baseline SDI [9], hypothetically as a result of lifestyle/behavioral changes increasing metabolic risk factors as the country develops. A drop of HSBP is then observed at high SDIs, when development is enough to allow for adequate BP control.

HSBP accounted for the highest proportion of deaths in 2017 in both sexes, followed by dietary risks and increased body mass index in women, with tobacco consumption prevailing over dietary risks for men. Regarding the leading causes of DALY, the overall pattern substantially changed as a reflex of the epidemiological transition, from child and maternal malnutrition in 1990 (with HSPB in the 4th position) to tobacco in 2017, followed by HSBP. These findings differ from those reported in 2015, when dietary risks-improved by successful strategies focused on diet and other health behaviors-were the main cause of DALYs [33]. On the other hand, a recent study observed a decrease in the smoking reduction trend, which varied from $-23.4 \%$ in the years $2010-2014$ to $-2.9 \%$ in the period $2015-2017$, even with an increase in prevalence in the population with $\geq 9$ years of schooling-an alarming trend, considering the successful anti-tobacco initiatives in the past decades. The authors point to one of the possible determinants: the fiscal austerity and the economic crisis that Brazil is currently experiencing [2], limiting the expansion of health education programs. These data point toward the need for individualized approaches for men and women in prevention and awareness programs, reinforcing-as examples-tobacco cessation for men, while focusing on dietary habits and obesity for women. HTN, for instance, must remain as a top priority for policy-making.

Ischemic heart disease and stroke remained as the first and second leading causes of age-standardized deaths and DALYs attributable to HSBP respectively, in both sexes, in 2017, in Brazil and its FU [34]. This suggests a more chronic end-organ damage profile, also deeply associated with other common risk factors such as tobacco, diabetes, and cardiometabolic factors [35]. Similar to aging, the growing impact of such factors-affecting ischemic diseases-can be understood as a product of the late epidemiological transition. Also, better access to healthcare seems to result in a more acute reduction of morbidity and mortality associated with kidney disease and hypertensive heart disease [13]. For the reduction of this burden, there has been much debate about adequate targets for blood pressure control and their clinical feasibility, as meta-analyses and primary data strongly suggest cardiovascular mortality benefits for a target SBP < $120 \mathrm{~mm} \mathrm{Hg}[13,36,37]$. These observations support the assumption that adequate SBP control modifies the associated mortality in a progressive fashion, although the precise subpopulations that benefit from intensive control and the optimal targets remain unclear [13]. The new BP target recommendations [35] have not yet been incorporated by Brazilian guidelines [4]. However, the ability to control determinants of HTN (e.g., diet, salt and alcohol intake, obesity) in the population may be more important than the unclear benefits of intensified BP targets.

Thus, cardiovascular health overall improved substantially in Brazil from 1990 to 2017, with important differences across the geographical regions of the country [38]. This reduction was more pronounced in the states in the southern and southeastern regions possibly being influenced by socioeconomic development $[39,40]$. Our findings from the GBD 2017 estimates reinforce these observations, pointing toward the need for a broad discussion about the directions of cardiovascular care in Brazil in the coming years. More than access to medical 
appointments, adequate long-term HTN control is highly dependent on population education to improve awareness and health promotion through a multidisciplinary approach, as well as improvement of the quality of care [6]. In part, this is the scope of the Family Health program that has been developed in the Brazilian primary care system since the 1990s, which should be further promoted [8]. Although it is necessary to provide universal access and high-quality healthcare, it is mandatory to also act on social determinants of health to sustainably reduce the burden of CVD [41].

\section{Limitations and strengths}

The limitations of the GBD study models have been previously detailed [9]. Despite the improvement in availability of primary data in Brazil from 1990 to 2017, the publications are still heterogeneous, and data are still scarce for some regions, especially the less resourced ones as the North and Northeast. However, the implementation of health surveys in the country with measured blood pressures, such as the "National Health Survey" (Pesquisa Nacional de Saúde-PNS) are recently improving the knowledge of the epidemiological profile of the population [3]. Furthermore, $140 \mathrm{mmHg}$ was the threshold for prevalence estimates, despite the changes in the 2017 American Heart Association/American College of Cardiology Guidelines driven by robust data [35, 36]. The past threshold, however, remains acceptable for a considerable proportion of the population. Also, of note, controlled HTN and isolated DBP were not considered for the estimates, although the latter is uncommon and unlikely to explain differences in prevalence. Although it is recognized that systolic values have stronger associations with health outcomes, these may also be sources of bias [13] accounting, along with abovementioned particularities of the GBD model, for the considerable lower prevalence of HSBP in comparison with primary HTN data. This precludes the direct comparison with other studies that used definitions that considered DBP and treated HTN, as mentioned, as different conditions are being measured. Finally, disability weights were not country-specific and may be prone to some imprecision, although some data has shown that they are relatively stable across different populations [14].

Despite the above limitations, GBD is a robust and broad epidemiological initiative, for estimating the morbidity and mortality due to HSBP in the entire Brazilian territory, especially in regions where primary data is scarce, where temporal-spatial complex models provide reliable estimates, previously unavailable $[9,13]$. The lack of precision of some aspects of the subnational models in Brazil-requiring a close evaluation of uncertainty intervals provided by GBD-does not affect the main findings and the contribution of this approach to evaluate the health impact of HSBP and help develop policies for its confrontation. The main strength of this study is to be, at the best of our knowledge, the most comprehensive countrywide data demonstrating the significant reduction of age-standardized death and DALY rates attributable to HSBP in Brazil, but also the maintenance of HSBP as the main risk factor for death in the country.

\section{Conclusion}

The age-standardized death rates attributable to HSBP are decreasing in Brazil, probably revealing the results of successful public health policies for CVD secondary prevention and control, markedly public campaigns and the availability of drug therapy in the public health system. However, prevalence data still shows a trend of increase that deserves to be confirmed by a new National Health Survey. Moreover, HSBP continues to be the main risk factor for death in the country and an increase in the total number of diseases attributable to HSBP in the near future is foreseen, mainly due to population aging and growth. These findings, along with the correlation between high SDI and the reduction in the burden attributable to HSBP, suggest that health policies must focus on healthy aging and the underserved population, emphasizing specific strategies for HTN screening, treatment, and adherence. Sensitization at different levels, from health policy-makers to civil society organizations, is crucial for the development of contemporary strategies to confront HSBP in Brazil in order to diminish the burden of health loss due to HSBP in the next decades.

\section{Supplementary information}

Supplementary information accompanies this paper at https://doi.org/10. 1186/s12963-020-00218-z.

Additional file 1. Global standard population distribution utilized by the Global Burden of Disease 2017 study.

Additional file 2: Table S3. All age deaths and DALYs in 1990 and 2017 and percent change of deaths and age-standardized death rates, DALYs, and age-standardized DALY attributable to high blood pressure, for cardiovascular diseases (total) and for each level 2 cardiovascular disease for both sexes (A), men (B), and women (C), in Brazil.

\section{Abbreviations}

BP: Blood pressure; BRICS: Brazil, Russia, India, China, and South Africa; CRA: Comparative Risk Analysis; CVD: Cardiovascular disease; DALY: Disabilityadjusted life years; DBP: Diastolic blood pressure; FU: Federal units; GBD 2017: Global Burden of Disease 2017 study; HSBP: High systolic blood pressure; HTN: Hypertension; PAF: Population-Attributable Fraction; RR: Relative risks; SDI: Sociodemographic index; SUS: Sistema Único de Saúde; TMREL: Theoretical minimum risk exposure level; VIGITEL: Vigilância de Fatores de Risco e de Proteção para Doenças Crônicas; YLD: Years lived with disability; YLL: Years of life lost; 95\% UI: 95\% uncertainty intervals

Acknowledgements

Not applicable. 


\section{About this supplement}

This article has been published as part of Population Health Metrics, Volume 18 Supplement 1 2020: The GBD Brazil Network. The full contents of the supplement are available at https://pophealthmetrics.biomedcentral.com/ articles/supplements/volume-18-supplement-1.

\section{Authors' contributions}

Study design, analysis and interpretation of the data, and drafting and critical review of the manuscript: BRN, LCCB, GMMO, VP, BD, and ALPR. Study design, data collection, analysis and interpretation of results, and revision of the final manuscript: SY, SDG, MM, MN, GR, DS, and DM. Critical review of the manuscript: VP, BD, DS, DM, and MN. The authors read and approved the final manuscript.

\section{Funding}

This study used data from IHME, funded by the Bill \& Melinda Gates Foundation. This work was supported by the Brazilian Ministry of Health through resource transfer from the National Health Fund (TED - 125/2017). Publication costs are funded by the Brazilian Ministry of Health through resource transfer from the National Health Fund (TED - 125/2017). DCM, BBD, ALPR, and IEM acknowledge funding from the National Council of Technological and Scientific Development (CNPq). These funding sources had no role in the study design, analyses, interpretation of the data, or decision to submit results. ALPR receives research grants from CNPq/Brazil (grants 465518/2014-1 and 310679/2016-8) and from the Fundação de Amparo à Pesquisa de Minas Gerais (FAPEMIG, Brazil; PPM-00428-17). BBD receives research grants from CNPq/Brazil (Bolsa de produtividade em pesquisa, 304467/2015-4) and IATS (465518/2014-1) and from the Instituto de Avaliação de Tecnologias em Saúde (IATS, Brazil; 465518/2014-1). BRN was supported in part by CNPq/Brazil (Bolsa de produtividade em pesquisa, 312382/2019-7), and by Edwards Lifesciences Foundation, USA (Every Heartbeat Matters Program 2020).

\section{Availability of data and materials}

The datasets used and/or analyzed during the current study are available from the corresponding author on reasonable request. Data we used in this article are publicly available online on the official website of Institute of Health Metrics and Evaluation (http://ghdx.healthdata.org/gbd-results-tool).

\section{Ethics approval and consent to participate}

The GBD study was approved by the Institutional Review Board of the University of Washington. There was no need to submit to this research to the local Institutional Review Boards, as the study was conducted in a public domain secondary database, without nominal identification, in accordance with Decree No. 7,724, May 16, 2012, and Resolution 510, of April 7, 2016. The GBD Brazil study was approved by the Institutional Review Board of the Universidade Federal de Minas Gerais, under the protocol CAAE 62803316.7.0000.5149. As no individual patient data was collected, consent to participate does not apply.

\section{Consent for publication}

Not applicable.

\section{Competing interests}

The authors have no competing conflicts of interest regarding this manuscript.

\section{Author details}

${ }^{1}$ Faculdade de Medicina, Universidade Federal de Minas Gerais, Belo Horizonte, MG, Brazil. ${ }^{2}$ Hospital das Clínicas, Universidade Federal de Minas Gerais, Avenida Professor Alfredo Balena, 110, Belo Horizonte, MG, Brazil. ${ }^{3}$ Institute for Health Metrics and Evaluation, University of Washington, Seattle, WA, USA. ${ }^{4}$ Faculdade de Medicina, Universidade Federal do Rio de Janeiro, Rio de Janeiro, RJ, Brazil. ${ }^{5}$ Faculdade Ciências Médicas de Minas Gerais, Belo Horizonte, MG, Brazil. ${ }^{6}$ Programa de Pós-graduação em Epidemiologia e Hospital de Clínicas de Porto Alegre, Universidade Federal do Rio Grande do Sul, Porto Alegre, RS, Brazil. ${ }^{7}$ Federal University of Santa Catarina, Research Center in Kinanthropometry and Human Performance, Florianópolis, SC, Brazil. ${ }^{8}$ Escola de Enfermagem, Universidade Federal de Minas Gerais, Belo Horizonte, MG, Brazil. ${ }^{9}$ Departamento de Vigilância de Doenças e Agravos Não Transmissíveis e Promoção da Saúde, Ministério da Saúde, Brasília, Brazil.
Received: 10 June 2020 Accepted: 10 July 2020

Published: 30 September 2020

\section{References}

1. Ribeiro AL, Duncan BB, Brant LC, Lotufo PA, Mill JG, Barreto SM. Cardiovascular health in Brazil: trends and perspectives. Circulation. 2016; 133(4):422-33.

2. Malta DC, Duncan BB, Barros MBA, Katikireddi SV, Souza FM, Silva AGD, Machado DB, Barreto ML. Fiscal austerity measures hamper noncommunicable disease control goals in Brazil. Cien Saude Colet. 2018; 23(10):3115-22.

3. Malta DC, Santos NB, Perillo RD, Szwarcwald CL. Prevalence of high blood pressure measured in the Brazilian population, National Health Survey, 2013. Sao Paulo Med J. 2016;134(2):163-70.

4. Malachias M, Plavnik FL, Machado CA, Malta D, Scala LCN, Fuchs S. 7th Brazilian Guideline of Arterial Hypertension: Chapter 1 - Concept, Epidemiology and Primary Prevention. Arq Bras Cardiol. 2016;107(3 Suppl 3):1-6.

5. Zhang Y, Moran AE. Trends in the prevalence, awareness, treatment, and control of hypertension among young adults in the United States, 1999 to 2014. Hypertension. 2017:70(4):736-42.

6. Macinko J, Leventhal DGP, Lima-Costa MF. Primary care and the hypertension care continuum in Brazil. J Ambul Care Manage. 2018;41(1): 34-46.

7. Chor D, Pinho Ribeiro AL, Sa Carvalho M, Duncan BB, Andrade Lotufo $P$, Araujo Nobre A, Aquino EM, Schmidt MI, Griep RH, Molina Mdel C, et al. Prevalence, awareness, treatment and influence of socioeconomic variables on control of high blood pressure: results of the ELSA-Brasil Study. PLOS One. 2015;10(6):e0127382.

8. Picon RV, Dias-da-Costa JS, Fuchs FD, Olinto MTA, Choudhry NK, Fuchs SC. Hypertension management in Brazil: usual practice in primary care-a metaanalysis. Int J Hypertens. 2017;2017:1274168.

9. Risk Factors Collaborators GBD. Global, regional, and national comparative risk assessment of 84 behavioural, environmental and occupational, and metabolic risks or clusters of risks for 195 countries and territories, 19902017: a systematic analysis for the Global Burden of Disease Study 2017. Lancet. 2018;392(10159):1923-94.

10. GBD DALYs and HALE Collaborators. Global, regional, and national disabilityadjusted life-years (DALYs) for 359 diseases and injuries and healthy life expectancy (HALE) for 195 countries and territories, 1990-2017: a systematic analysis for the Global Burden of Disease Study 2017. Lancet. 2018; 392(10159):1859-922.

11. GBD Disease and Injury Incidence and Prevalence Collaborators. Global, regional, and national incidence, prevalence, and years lived with disability for 354 diseases and injuries for 195 countries and territories, 1990-2017: a systematic analysis for the Global Burden of Disease Study 2017. Lancet. 2018:392(10159):1789-858

12. Global Burden of Disease 2015 study: summary of methods used. Rev Bras Epidemiol. 2017:20(Suppl 01):4-20.

13. Forouzanfar MH, Liu P, Roth GA, Ng M, Biryukov S, Marczak L, Alexander L, Estep K, Hassen Abate K, Akinyemiju TF, et al. Global burden of hypertension and systolic blood pressure of at least 110 to $115 \mathrm{~mm} \mathrm{Hg}$, 1990-2015. JAMA. 2017;317(2):165-82.

14. Salomon JA, Haagsma JA, Davis A, de Noordhout CM, Polinder S, Havelaar AH, Cassini A, Devleesschauwer B, Kretzschmar M, Speybroeck N, et al. Disability weights for the Global Burden of Disease 2013 study. Lancet Glob Health. 2015;3(11):e712-23.

15. Singh GM, Danaei G, Farzadfar F, Stevens GA, Woodward M, Wormser D, Kaptoge S, Whitlock G, Qiao Q, Lewington S, et al. The age-specific quantitative effects of metabolic risk factors on cardiovascular diseases and diabetes: a pooled analysis. PLoS One. 2013;8(7):e65174.

16. Haagsma JA, Maertens de Noordhout C, Polinder S, Vos T, Havelaar AH, Cassini A, Devleesschauwer B, Kretzschmar ME, Speybroeck N, Salomon JA. Assessing disability weights based on the responses of 30,660 people from four European countries. Popul Health Metrics. 2015;13:10.

17. Das Gupta P. Standardization and decomposition of rates from crossclassified data. Genus. 1994:50(3-4):171-96.

18. GBD SDG Collaborators. Measuring progress from 1990 to 2017 and projecting attainment to 2030 of the health-related Sustainable Development Goals for 195 countries and territories: a systematic analysis for the Global Burden of Disease Study 2017. Lancet. 2018; 392(10159):2091-138. 
19. NCD Risk Factor Collaboration. Worldwide trends in blood pressure from 1975 to 2015: a pooled analysis of 1479 population-based measurement studies with 19.1 million participants. Lancet. 2017;389(10064):37-55.

20. Vigitel Brasil 2017. Vigilância de fatores de risco e proteção para doenças crônicas por inquérito telefônico: estimativas sobre frequência e distribuição sociodemográfica de fatores de risco e proteção para doenças crônicas nas capitais dos 26 estados brasileiros e no Distrito Federal em 2017. In: Volume 2018, 1st edn. Brasília: Ministério da Saúde. Secretaria de Vigilância em Saúde. Departamento de Vigilância de Doenças e Agravos não Transmissíveis e Promoção da Saúde. p. 2018.

21. Malta DC, Stopa SR, Iser BP, Bernal RT, Claro RM, Nardi AC, Dos Reis AA, Monteiro CA. Risk and protective factors for chronic diseases by telephone survey in capitals of Brazil, Vigitel 2014. Rev Bras Epidemiol. 2015;18(Suppl 2):238-55

22. Picon RV, Fuchs FD, Moreira LB, Riegel G, Fuchs SC. Trends in prevalence of hypertension in Brazil: a systematic review with meta-analysis. PLoS One. 2012;7(10):e48255.

23. Hernandez EM, Margolis R, Hummer RA. Educational and gender differences in health behavior changes after a gateway diagnosis. J Aging Health. 2018; 30(3):342-64.

24. Malta DC, Andrade SC, Claro RM, Bernal RT, Monteiro CA. Trends in prevalence of overweight and obesity in adults in 26 Brazilian state capitals and the Federal District from 2006 to 2012. Rev Bras Epidemiol. 2014; 17(Suppl 1):267-76.

25. Telo GH, Cureau FV, de Souza MS, Andrade TS, Copes F, Schaan BD. Prevalence of diabetes in Brazil over time: a systematic review with metaanalysis. Diabetol Metab Syndr. 2016;8(1):65

26. Roth GA, Forouzanfar MH, Moran AE, Barber R, Nguyen G, Feigin VL, Naghavi M, Mensah GA, Murray CJ. Demographic and epidemiologic drivers of global cardiovascular mortality. N Engl J Med. 2015;372(14):1333-41.

27. GBD Mortality Collaborators. Global, regional, and national age-sex-specific mortality and life expectancy, 1950-2017: a systematic analysis for the Global Burden of Disease Study 2017. Lancet. 2018;392(10159):1684-735.

28. Plano de ações estratégicas para o enfrentamento das doenças crônicas não transmissíveis (DCNT) no Brasil 2011-2022 [Internet, date accessed: September 3, 2019]. In. Brasília: Ministério da Saúde, Secretaria de Vigilância em Saúde - Departamento de Análise de Situação de Saúde, Coordenação Geral de Doenças e Agravos Não Transmissíveis; 2011.

29. Global action plan for the prevention and control of noncommunicable diseases 2013-2020 [Internet, date accessed: September 3, 2019] [http:// apps.who.int/iris/handle/10665/94384].

30. Sustainable Delepment Goals 2030 [https://www.un.org/ sustainabledevelopment/], date accessed: September 3, 2019.

31. Villela PB, Klein CH, Oliveira GMM. Socioeconomic factors and mortality rates due to cerebrovascular and hypertensive diseases in Brazil. Rev Port Cardiol. 2019;38(3) Epub ahead of print.

32. Síntese de indicadores sociais: uma análise das condições de vida da população brasileira, vol. 1. Rio de Janeiro: Instituto Brasileiro de Geografia e Estatística (IBGE), Coordenação de População e Indicadores Sociais.; 2017.

33. Malta DC, Felisbino-Mendes MS, Machado IE, Passos VMA, Abreu DMX, Ishitani LH, Velasquez-Melendez G, Carneiro M, Mooney M, Naghavi M. Risk factors related to the global burden of disease in Brazil and its Federated Units, 2015. Rev Bras Epidemiol. 2017;20(Suppl 01):217-32.

34. GBD Causes of Death Collaborators. Global, regional, and national age-sexspecific mortality for 282 causes of death in 195 countries and territories, 1980-2017: a systematic analysis for the Global Burden of Disease Study 2017. Lancet. 2018;392(10159):1736-88.

35. Whelton PK, Carey RM, Aronow WS, Casey DE Jr, Collins KJ, Dennison Himmelfarb C, DePalma SM, Gidding S, Jamerson KA, Jones DW, et al. 2017 ACC/AHA/AAPA/ABC/ACPM/AGS/APhA/ASH/ASPC/NMA/PCNA guideline for the prevention, detection, evaluation, and management of high blood pressure in adults: executive summary: a report of the American College of Cardiology/American Heart Association Task Force on Clinical Practice Guidelines. Circulation. 2018;138(17):e426-83.

36. Group SR, Wright JT Jr, Williamson JD, Whelton PK, Snyder JK, Sink KM, Rocco MV, Reboussin DM, Rahman M, Oparil S, et al. A randomized trial of intensive versus standard blood-pressure control. N Engl J Med. 2015; 373(22):2103-16

37. Ettehad D, Emdin CA, Kiran A. Blood pressure lowering for prevention of cardiovascular disease and death: a systematic review and meta-analysis. Lancet. 2016;387(10022):957-67.
38. GBD Brazil Collaborators. Burden of disease in Brazil, 1990-2016: a systematic subnational analysis for the Global Burden of Disease Study 2016. Lancet. 2018;392(10149):760-75.

39. Brant LCC, Nascimento BR, Passos VMA, Duncan BB, Bensenor IJM, Malta DC, Souza MFM, Ishitani LH, Franca E, Oliveira MS, et al. Variations and particularities in cardiovascular disease mortality in Brazil and Brazilian states in 1990 and 2015: estimates from the Global Burden of Disease. Rev Bras Epidemiol. 2017;20(Suppl 01):116-28.

40. Allen L, Williams J, Townsend N, Mikkelsen B, Roberts N, Foster C, Wickramasinghe K. Socioeconomic status and non-communicable disease behavioural risk factors in low-income and lower-middle-income countries: a systematic review. Lancet Glob Health. 2017;5(3):e277-89.

41. Donkin A, Goldblatt P, Allen J, Nathanson V, Marmot M. Global action on the social determinants of health. BMJ Glob Health. 2018;3(Suppl 1): e000603.

\section{Publisher's Note}

Springer Nature remains neutral with regard to jurisdictional claims in published maps and institutional affiliations.

\section{Ready to submit your research? Choose BMC and benefit from:}

- fast, convenient online submission

- thorough peer review by experienced researchers in your field

- rapid publication on acceptance

- support for research data, including large and complex data types

- gold Open Access which fosters wider collaboration and increased citations

- maximum visibility for your research: over $100 \mathrm{M}$ website views per year

At BMC, research is always in progress.

Learn more biomedcentral.com/submissions 